\title{
Recent Advances in Vibration Control Methods for Wind Turbine Towers
}

\author{
Georgios Malliotakis ${ }^{1}\left(\mathbb{D}\right.$, Panagiotis Alevras ${ }^{1, *}$ and Charalampos Baniotopoulos ${ }^{2} \mathbb{D}$ \\ 1 Department of Mechanical Engineering, School of Engineering, University of Birmingham, \\ Birmingham B15 2TT, UK; gxm054@bham.ac.uk \\ 2 Department of Civil Engineering, School of Engineering, University of Birmingham, \\ Birmingham B15 2TT, UK; c.baniotopoulos@bham.ac.uk \\ * Correspondence: p.alevras@bham.ac.uk
}

Citation: Malliotakis, G.; Alevras, P.; Baniotopoulos, C. Recent Advances in Vibration Control Methods for Wind Turbine Towers. Energies 2021, 14, 7536. https://doi.org/10.3390/ en14227536

Academic Editor: Jari Hämäläinen

Received: 31 August 2021

Accepted: 12 October 2021

Published: 11 November 2021

Publisher's Note: MDPI stays neutral with regard to jurisdictional claims in published maps and institutional affiliations.

Copyright: (c) 2021 by the authors. Licensee MDPI, Basel, Switzerland. This article is an open access article distributed under the terms and conditions of the Creative Commons Attribution (CC BY) license (https:// creativecommons.org/licenses/by/ $4.0 /)$.
Abstract: Wind power is a substantial resource to assist global efforts on the decarbonization of energy. The drive to increase capacity has led to ever-increasing blade tip heights and lightweight, slender towers. These structures are subject to a variety of environmental loads that give rise to vibrations with potentially catastrophic consequences, making the mitigation of the tower's structural vibrations an important factor for low maintenance requirements and reduced damage risk. Recent advances in the most important vibration control methods for wind turbine towers are presented in this paper, exploring the impact of the installation environment harshness on the performance of state-of-the-art devices. An overview of the typical structural characteristics of a modern wind turbine tower is followed by a discussion of typical damages and their link to known collapse cases. Furthermore, the vibration properties of towers in harsh multi-hazard environments are presented and the typical design options are discussed. A comprehensive review of the most promising passive, active, and semi-active vibration control methods is conducted, focusing on recent advances around novel concepts and analyses of their performance under multiple environmental loads, including wind, waves, currents, and seismic excitations. The review highlights the benefits of installing structural systems in reducing the vibrational load of towers and therefore increasing their structural reliability and resilience to extreme events. It is also found that the stochastic nature of the typical tower loads remains a key issue for the design and the performance of the state-of-the-art vibration control methods.

Keywords: vibration control; wind turbine tower; review; tuned mass damper; tuned liquid column damper; multi-hazard

\section{Introduction}

In recent decades, climate change has been gradually becoming a major societal challenge due to high levels of $\mathrm{CO}_{2}$ and other hazardous emissions. Since the global population is increasing rapidly, worldwide energy demand is consequently increasing. Energy is primarily produced by fossil fuels releasing high emissions of $\mathrm{CO}_{2}$. For example, natural gas is the primary fuel for electricity production in the UK, accounting for $38.2 \%$ of the total energy [1]. Thus, the greenhouse effect is exacerbated, and global warming is becoming more and more evident throughout the world, not least through severe natural hazards that are related to climate change. To tackle this problem, the UN set the goal of limiting global warming below $2{ }^{\circ} \mathrm{C}$ compared to pre-industrial levels according to the celebrated Paris Agreement [2]. This necessary and ambitious aim is a major societal challenge, which in many respects is subject to the decarbonization of energy production.

Renewable energy sources are considered the most promising way to decarbonize energy production. The European Union (EU) has defined a 32\% global quota for renewable energy sources by 2030, whereas recently the European Commission adopted the "Fit for 55" package of policies [3], aiming to reduce emissions by $55 \%$ by 2030 compared to 1990 levels. 
Wind energy is widely accepted as a promising technological solution to contribute to this crucial target. Wind is an inexhaustible and green source of energy. Each kilowatt per hour of electricity generated by the wind replaces a corresponding value generated by fossils that heavily pollute the environment. Wind energy already holds a significant place in the European energy mix, since $15 \%$ of the EU's electricity demands are covered by wind, with the majority of this being captured by onshore wind farms [4]. There is plenty of interest among industry and researchers to increase the efficiency and capacity of the captured wind energy. Furthermore, EU member states aim for a $64 \%$ increase in the onshore wind capacity in order to deliver their National Energy and Climate Plan [5]. According to UK Energy Trends [1], electricity produced by renewables increased in 2019 and matched fossil fuels in 2020, consisting of $42 \%$ of the total generated energy. In the UK, wind power was the dominant source of renewable energy as it covered $27 \%$ of the total energy demand for 2020 [6].

Wind energy is captured by Wind Turbines (WT), which convert the kinetic energy of the wind to electrical power. A wind turbine consists of the rotor hub, the nacelle, and the blades, supported by wind turbine towers. The evaluation of a wind turbine is based on two basic parameters, the height of the tower and the wind potential of the location [7]. It is more likely that the wind turbine is more efficient at higher heights due to the increased wind speeds. Installing WTs at ever-increasing heights is therefore an area for continuous improvement and structural innovation. However, it is obvious that the constructional cost increases in proportion to the tower's height. The tower plays an important role in the overall constructional cost, since the Levelized Cost of Energy (LCOE) and the competitiveness of the harnessed energy are affected by the structural cost. On average, the tower accounts for $15-20 \%$ of the total cost, in which the manufacture, transportation, and erection phases should be considered to provide an accurate estimation [8]. Hence, a design combining increased height and lower cost of the tower would lead to more competitive LCOE.

The majority of wind turbines are land-based [9]. There is plenty of interest among industry and the research community to make WTs much more efficient and productive. Although wind energy is an inexhaustible and green source of energy, certain parameters are making onshore wind energy less attractive. According to previous studies, onshore wind farms installed near inhabited areas are faced with dubious acceptance due to the visual aspect [10]. In addition, acoustic nuisance, caused by mechanical components and aerodynamic noise, is a reason for concern in local communities and local business ecosystems (e.g., tourism). Last but not least, large areas of land are required for new wind farms to respond to the increasing energy demand [11], which often raises concerns over the preservation of forests and natural wildlife habitats. Despite these disadvantages and considering that WTs are typically designed to last for about 20-25 years, repowering could be an option to increase the capacity of existing plants without occupying extra land [12]; yet, repowering is limited by the structural bearing capacity of the tower. Offshore wind turbine technology could be an alternative option, of which technology readiness grows at a rapid pace, promising to take advantage of stronger wind speeds and the availability of large areas in the sea [13]. The UK Government plans to invest in offshore wind energy, increasing its capacity to $40 \mathrm{GW}$ by 2030 [14] and EU members' [4] target of $40 \mathrm{GW}$ overall of offshore wind energy production. However, to fulfil the above goals, offshore wind energy should overcome difficulties such as higher contraction costs, limited accessibility, a harsh and corrosive environment, and interconnections with the onshore grid [15].

In this paper, recent advances in vibration control methods of wind turbine towers are discussed, attempting to link the performance of advanced control methods with known structural resilience issues in harsh, multi-faceted environments. Section 2 presents an overview of established characteristics and recent trends in the design of onshore and offshore wind turbine towers, including floating structures. Particular attention is paid to the different tower concepts and their foundations, as well as to the connections of the structural components, which play a key role in the structure's resistance. Section 3 
presents the typical vibration issues faced by modern wind energy converters. The impact of multiple load sources with the relatively unpredictable nature on the structure's resilience and the risk of collapse are discussed. Section 4 presents the most common vibration control methods that are explored in the literature for the mitigation of excessive WTT response, including passive, active, and semi-active approaches. The performance of recently proposed concepts is assessed against the reduction of the vibration response metrics, attempting to identify the adaptability of recent concepts to unpredictable loads. Last, the conclusions stemming from this comprehensive review are presented.

\section{Wind Turbine Tower Structures}

The typical structural characteristics of WTTs determine the properties of their loading response to a significant extent. Steel and concrete are the principal materials for wind turbine towers [16]. There are three basic design features for steel structures: Tubular, lattice, or hybrid towers, with the latter combining a lattice structure at the lower part and a tubular structure at the upper part [17]. In addition, composite towers could be a competitive alternative due to the cost reduction that may be achieved [18]. Additionally, the system modes and frequencies depend on the type and condition of the foundation. Besides, as it is described in Section 3, most studies on the vibration control of WTTs approach the problem as a reduced-usually linearized—system of oscillators, largely neglecting design features that are central in the evaluation or prediction of the structural integrity of a WTT. Therefore, in this section, an overview of WTT structures is given and the critical issues in terms of load-bearing capacity are explored.

\subsection{Steel Towers}

\subsubsection{Tubular Towers}

Tubular towers are the most common design feature to support the rotor nacelle assembly (Figure 1). They consist of cylindrical or conical sections of 20-30 m, which are transported and mounted on site. The sections are connected with bolted flanges using pre-stressed bolts. Cylindrical shells benefit from high load-bearing capacity compared to their thickness, reducing material use. In addition, tubular towers are designed as simple cantilever beams permitting simple calculations for cross-section selection [19]. Taller towers require a larger diameter at the base of the structure. However, there is a limit in regard to the diameter of the sections that can be transported through public highways, which is $4.5 \mathrm{~m}$. Furthermore, the thickness should be lower than $75 \mathrm{~mm}$ since thicker sections would be more difficultly curved.

Lavassas et al. represented a prototype wind turbine tower located in Laconia, Greece. They simulated all the details of the towers, including stiffening rings, flanges, manholes, and the foundation. An analytical model accurately determines the local stress concentrations [20]. Similarly, Bazeos et al. indicated that even though a simple model can predict the critical buckling load, an analytical model can predict the stress values at critical zones [21]. Both studies noted that openings are areas where high values of stress develop.

Moreover, the existence of manholes affects the system's structural resistance. Dimopoulos and Gantes carried out an experimental and numerical analysis to define the buckling resistance of wind turbine tower tubular shells with openings and stiffeners [22]. Openings were found to reduce the strength by about $24 \%$ but an appropriate stiffened scheme recovered this loss. Furthermore, the numerical and experimental results showed excellent agreement in the case of shells without openings and shells with stiffened openings. Moreover, different types of stiffeners (Figure 2) were considered to evaluate their effectiveness [23]. The two stringers and the ring stiffener were found to provide the most promising results, directing the failure mode outside the cut-off region. Moreover, Santos et al. concluded that the increase in stiffeners thickness did not necessarily increase the strength of the tower [24]. Even though the stiffening of holes proved successful, imperfections may also affect the structural response. Since tapered circular shells are very sensitive to imperfection, Yadav and Gerasimidis proposed a wavy tapered shell, noting that wavy 
cylinders significantly reduce the imperfections, thus improving the bending capacity of the tower [25].

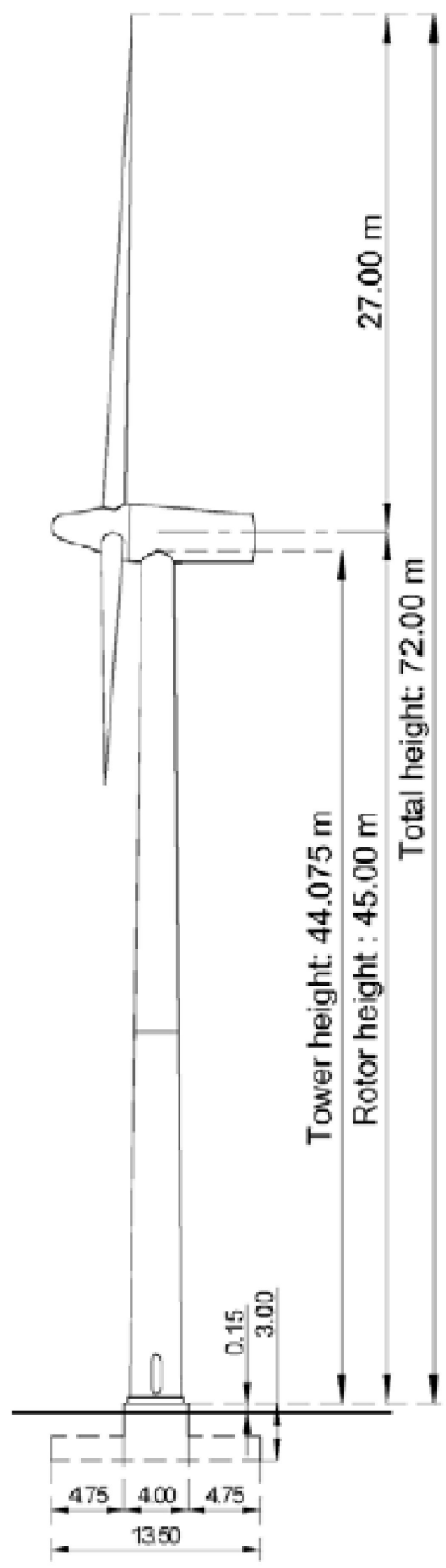

(a)

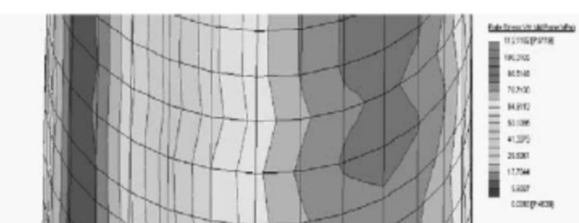

(b)

Figure 1. (a) Steel tubular tower sketch and dimensions; (b) FEM model of base with openings [20].
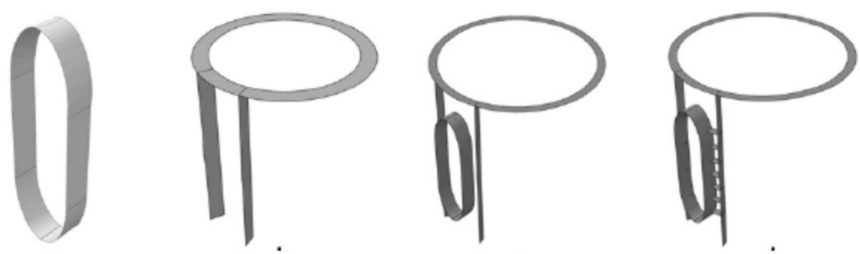

Figure 2. Different stiffening configurations for wind tower manholes [23]. 


\subsubsection{Lattice Towers}

Lattice towers (Figure 3) were the main design feature until the mid 1980s when they were substituted by a tubular tower, despite being lightweight with high levels of bearing capacity. Muskulus [26] reported the main advantages and drawbacks of lattice towers compared with the conventional tubular tower. The most significant point indicated is the material reduction achieved by using lattice towers instead of monopiles. A structural comparison between 76.15 and $105 \mathrm{~m}$ lattice and tubular towers was carried out [17], concluding that lattice towers are $40 \%$ lighter and $15 \%$ cheaper than tubular towers. In terms of the Life Cycle Assessment, it was found that a lattice tower and its foundation have a lower environmental impact since it contributes $32 \%$ less $\mathrm{CO}_{2}$ in the construction phase [27]. To reduce the connections of lattice towers, a polygonal cross-section with nine faces was introduced [28]. In this contribution, the plates work as a complete cross-section. However, lattice towers are typically used for small wind turbines (up to $300 \mathrm{~kW}$ ).

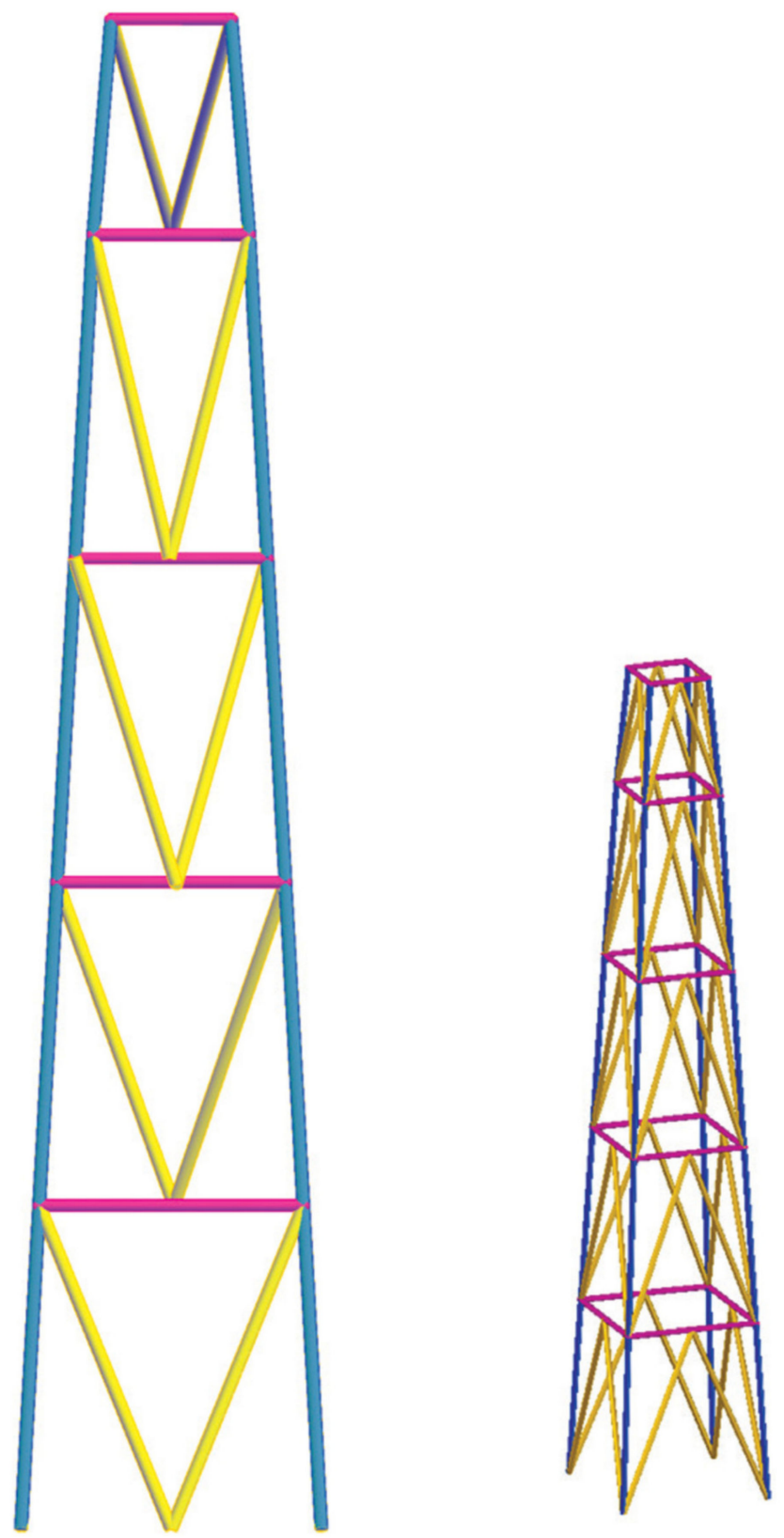

Figure 3. Lattice Steel Towers [27]. 


\subsection{Concrete Towers}

Concrete offers flexibility in the design and construction process, with fewer limitations on the tower height or the size of the sections. To avoid constructional issues of steel components, concrete could be a promising alternative. Taller towers need larger steel cross-sections, which may not be easily transportable as indicated above. Von der Haar and Marx [29] presented different design aspects for concrete wind turbine towers. They identified two main construction types of concrete towers, cast-in-place and precast concrete towers (Figure 4). Precast concrete is manufactured with high-quality standards offering short processing times. Moreover, precast concrete can show superior behavior under harsh environmental conditions since it does not require maintenance. Pre-cast concrete provides stability to resist collapse, which, combined with steel reinforcement, increases ductility. In general, the benefits of the use of concrete include increased structural stability, lower maintenance costs, on-site manufacturing, and higher stiffness controlling the eigenfrequencies and the lateral displacements of the tower [30]. The structural performance of steel and concrete towers was compared in terms of fragility curves. For the same level of wind speeds, steel towers showed higher probabilities of limit state exceedance [31]. De Lana et al. studied the behavior of prestressed concrete wind turbine towers with a circular cross-section [30]. They concluded that circular cross-sections are less expensive compared to the tower with octagonal sections because no internal rings are needed. Nevertheless, even octagonal prestressed wind turbine towers could be $15 \%$ cheaper than steel towers [32]. To tackle penetrating corrosion, Jin and Li introduced a lightweight fiber-reinforced cementitious composite to increase the durability of concrete structures, extending the service life of the tower with less maintenance [33].

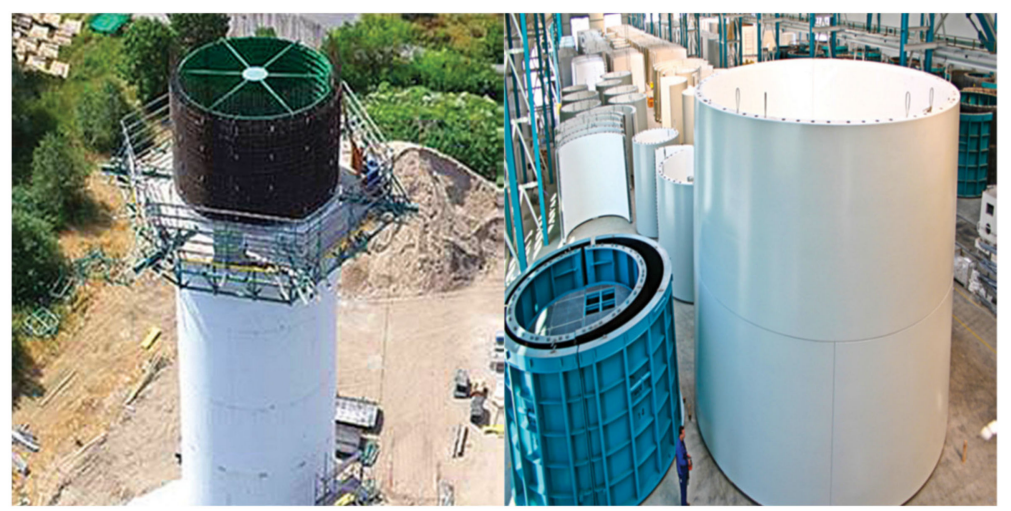

Figure 4. In-cast (left) and precast sections of concrete towers [29].

\subsection{Hybrid Towers}

\subsubsection{Composite Towers}

Composite materials are a promising alternative for wind turbine towers. In general, composites present a high specific stiffness, strength-to-weight ratio, and corrosion resistance. Moreover, they can be produced on-site, significantly reducing the transportation cost and making their assembly easier for large towers [34]. Two types of composites perspectives have been proposed: Sandwich towers and fiber-reinforced composites. Schaumann and Keindof studied different sandwich methods for WTTs [35]. Two steel monocoque towers with different steel qualities (S235 and S460) were compared with sandwich steel-grout-steel and steel-elastomer-steel shells. They concluded that combining high-strength steels with core materials could increase buckling resistance. An optimal combination of geometry and material properties of sandwich towers was studied as well [36], combing both maximum elastic moment resistance and stiffness. However, the effect of the additional mass was not considered to be related to the dynamic behavior of the tower. Thus, a sandwich lower part and a solid upper part could be proposed. Introducing a glass epoxy skin part, the manufacturing cost can be reduced by $25 \%$ compared to a steel 
tower [18]. Glass-fiber-reinforced epoxy resin was found to be $34 \%$ lighter than a steel tower, fulfilling ultimate and fatigue load requirements [37]. Experimental and finite element analysis was carried out to assess the static and dynamic behavior of glass-fiber-reinforced wind turbine towers. Good agreement between finite elements and experimental analysis was observed for the structural and dynamic behavior of the structure. Nevertheless, two main types of failures were observed through the experimental analysis, namely the shear failure taking place on the fibers and the local buckling on the tower [38].

\subsubsection{Hybrid Lattice-Tubular Towers}

This hybrid tower consists of a bottom lattice and an upper tubular tower connected with a transition piece (Figure 5). The combination of lattice and tubular towers allows them to take advantage of both processes, overcoming the transportation limits and maintenance costs due to the bolted connections in the case of tubular and lattice towers.

Mohammadi studied different aspects of hybrid towers, considering a four- or a six-lattice tower for a variety of lattice or tubular height towers [39]. After performing structural and dynamic analysis, it was concluded that a six-legged tower with a $45^{\circ}$ bracing system and $4 / 1$ or $5 / 1$ height/spread ratios resulted in the least structural mass and bolts. Focusing only on the lower lattice part, Jovasevic suggested that K bracing with a $4 / 1$ height/spread ratio is the optimal solution for reducing the mass of the tower and the number of bolts [40]. The structural response of a $120 \mathrm{~m}$ hybrid tower (60 m lattice and $60 \mathrm{~m}$ tubular) was investigated [41] using a cold-formed polygonal cross-section for both parts, concluding that the maximum bending, axial loads, and deflections were achieved for a wind speed of $11 \mathrm{~m} / \mathrm{s}$. In terms of Life Cycle Assessment, the hybrid towers can operate at greater heights, increasing energy production, leading to approximately the same environmental footprint compared with conventional steel tubular towers [42].

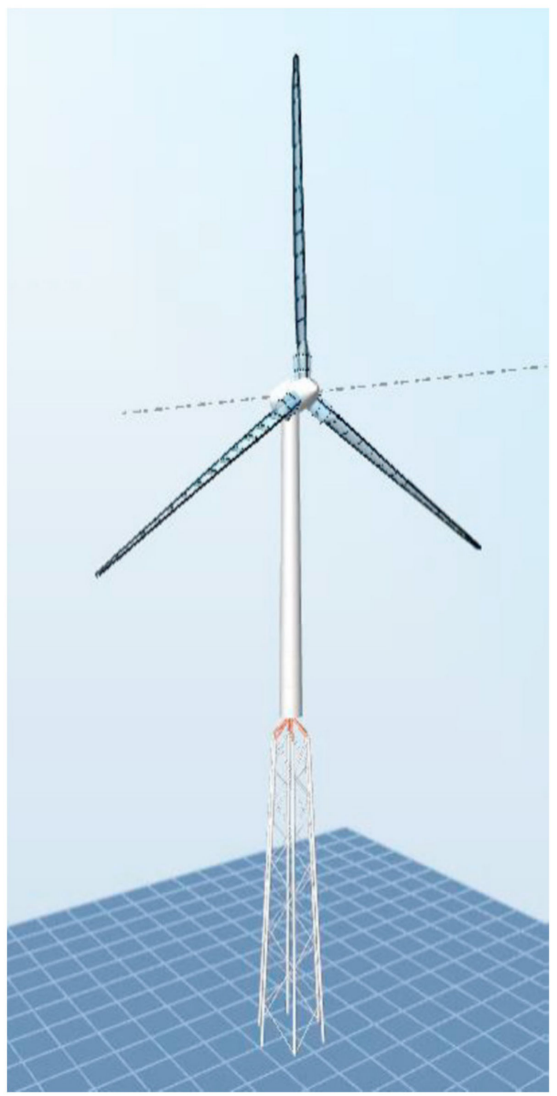

Figure 5. Hybrid lattice-tubular tower [41]. 


\subsubsection{Hybrid Concrete-Steel Towers}

Steel and concrete towers can be used together, introducing a hybrid concrete-steel tower. This new concept was proposed to take advantage of the benefits of each tower type. In regard to the erection phase, the upper steel part can easily be prefabricated and assembled. The concrete part offers higher flexural stiffness than a full steel tower, allowing it to control the frequencies of the system, as well as reducing the overall mass.

The Technische Hochschule Mittelhessen (University of Applied Sciences) in the State of Hesse in Germany proposed a novel steel-concrete tower (Figure 6) [43]. The concrete tower consists of prefabricated quarter-circle elements, connected with steel frameworks, while the upper part is a tubular steel shell. Considering this design feature, material savings were estimated at around $40 \%$ in comparison with a full concrete tower, reducing the overall assembly and transportation process costs. Özdemir et al. conducted structural analysis of steel, concrete, and hybrid steel-concrete towers [44]. The hybrid tower presents lower displacements by about $44.16 \%$ compared with the steel one. However, the hybrid tower does not show any significant advantages in terms of structural costs over the traditional steel tower. In addition, a steel hybrid tower is sensitive to seismic vibrations and thus, a large foundation is needed to withstand the seismic forces [45].
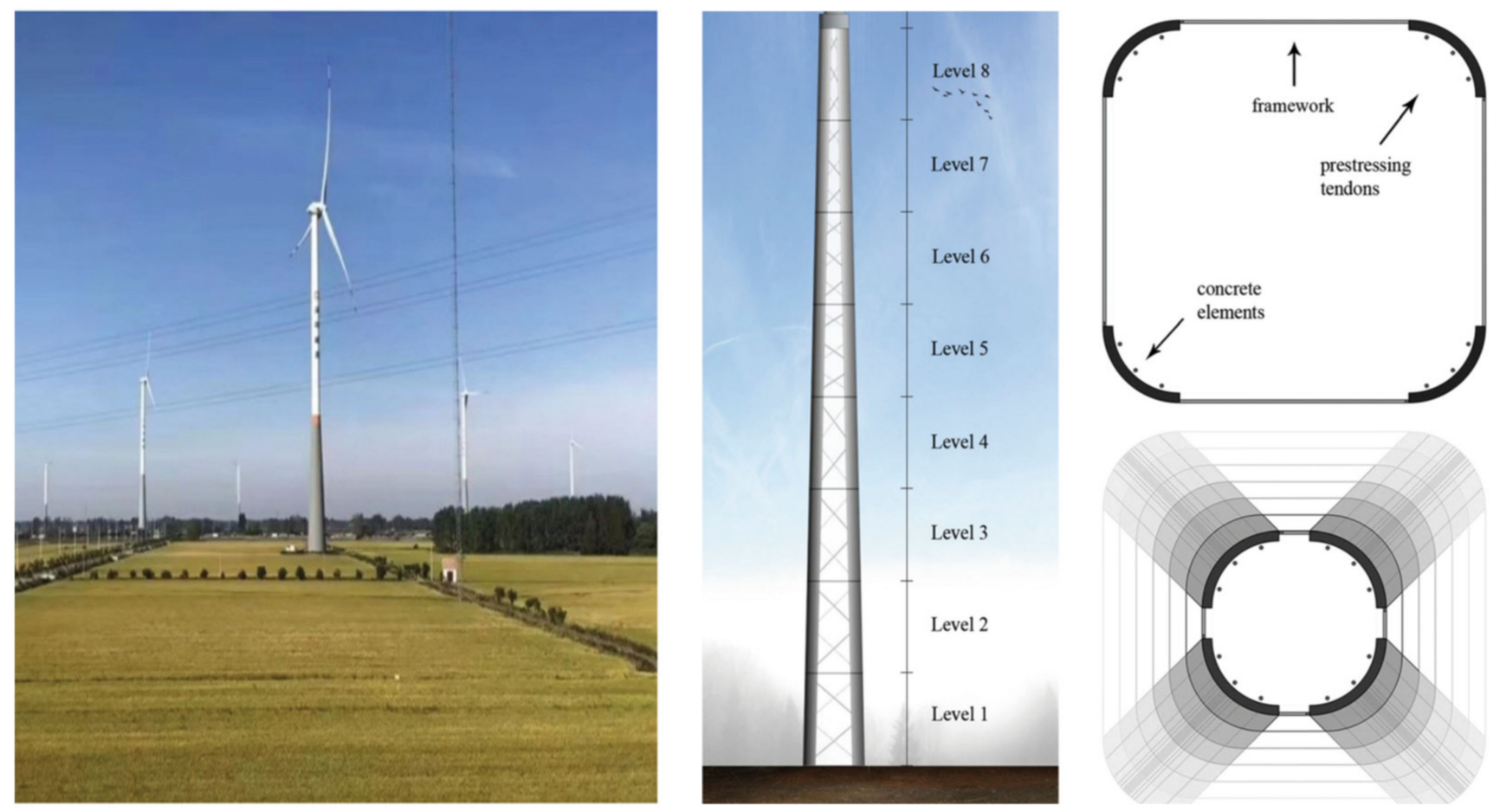

Figure 6. Novel hybrid steel-concrete tower [43].

\subsubsection{Onshore Foundations}

Onshore foundations contribute to around $30 \%$ of the total cost of the tower [46], contributing $24 \%$ of the total global warming emissions of material components for a typical 2 MW [47]. In general, two main categories can be considered for wind turbine foundations, namely spread foundations and piled foundations (Figure 7) [48].

Spread foundations are mainly used for stiff and high-strength soils. There are two main types of spread foundations, the shallow foundation and gravity foundations. Shallow foundations rest on the ground without additional excavations. On the contrary, gravity foundations are placed below ground level. This takes advantage of better-quality soil located below the surface by excavating the soil. 


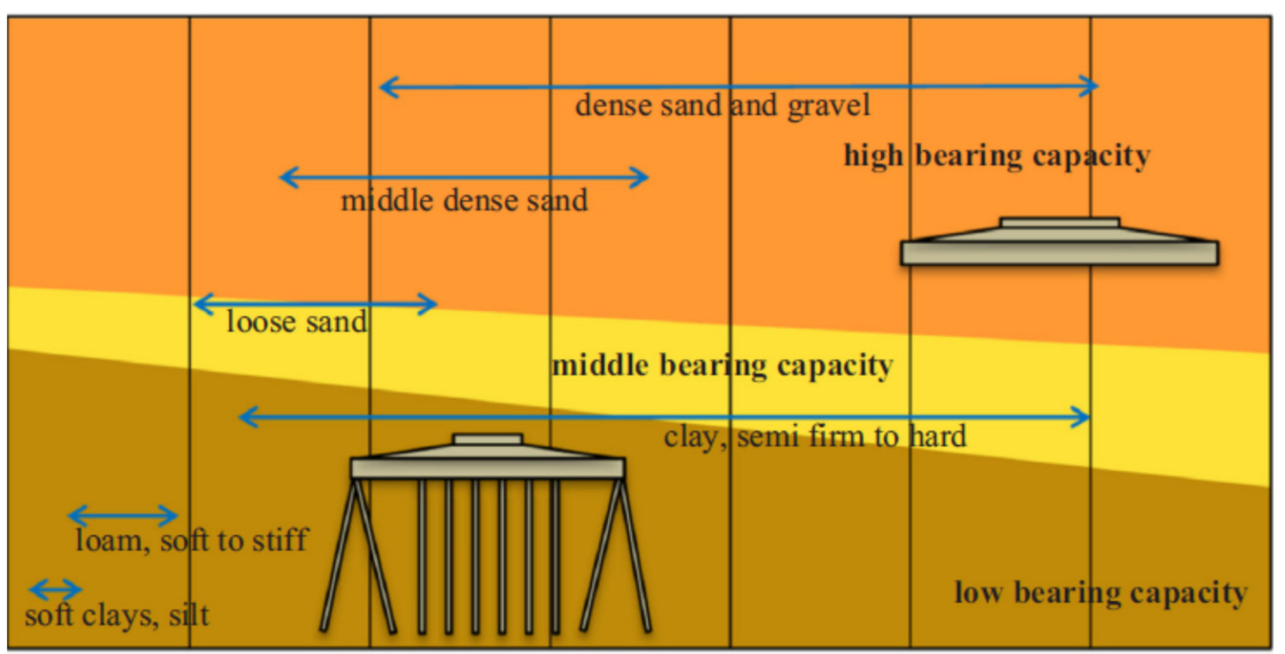

Figure 7. Different types of onshore foundations depending on the quality of soil [49].

Pile foundations are a suitable and sustainable solution for soft and low-strength soil. The piles transfer the load to deeper soil layers with high-bearing capacity. Furthermore, they can be used to avoid large settlements. The piles can be anchored in bedrock if bedrock is identified at a reasonably shallow depth. In that way, tension loads from the tower are transferred to the bedrock. When resting on soft soil, the soil-structure interaction (SSI) should be examined; however, it has been found that for pile foundations, this effect is not important [49]. When bedrock is located deeper, a piled raft foundation is considered, which is a combination of a spread foundation with a group of piles. The first part spreads the load at the upper part of the foundation and the piles transfer the loads to the deeper and stronger soil layers. The number of piles and the depth selection should be determined to provide enough bearing capacity and small settlements. In addition, a hybrid foundation solution with a shallow foundation and steel micro piles was proposed [50]. The scheme can be used to retrofit existing, or to build new, foundations, aiming at tensile mobilization and compression improvement. Moreover, the existence of micro piles will make the foundation stiffer, reducing the vibrations of the wind turbine. Finally, this foundation configuration leads to a more sustainable solution compared with the traditional shallow foundation since a reduction of $15-54 \%$ and $30-53 \%$ is achieved for concrete and steel, respectively [46].

\subsubsection{Offshore Foundations}

The design of offshore foundations depends on the depth of the water and the soil conditions [16]. The water depths are classified by three main categories, shallow $(0-30 \mathrm{~m})$, transitional (30-50 m), and deep water $(>50 \mathrm{~m})$. Due to their complexity, offshore wind turbine foundations are more expensive than the respective onshore foundations. Moreover, the transportation and installation of foundation components are serious issues to deal with [51]. A tubular design configuration is selected for offshore wind turbine towers. The tower is connected to the substructure through a transition piece, transferring the loads at the seabed foundation.

\section{Gravity Base Foundation}

The design of gravity-base foundations (Figure $8 \mathrm{~b}$ ) of offshore wind turbines is primarily according to their self-weight, which must be sufficient to resist extreme overturning moments, leaving support structures standing upright on the seabed. A gravity-based foundation is preferred for very shallow waters, occasionally under $10 \mathrm{~m}$. As a type of reinforced concrete caisson structure, the gravity base is simple to construct and has a relatively low load-bearing capacity. Given that the gravity base requires sufficient loadbearing capacity to support the self-weight, service loads, and environmental loads acting 
on the foundation structures, gravity-base foundations are more appropriate for seabed composed of compacted clay, sandy soil, and rock.

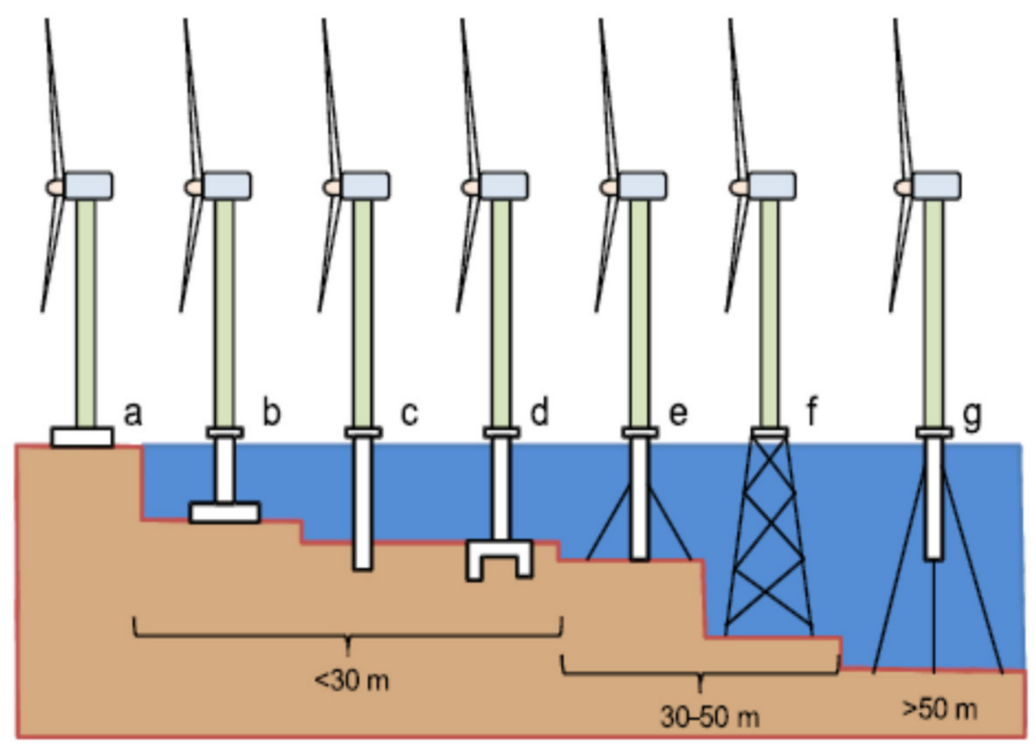

Figure 8. Different types of offshore wind turbine foundations: (a) Onshore (b) gravity base; (c) monopile; (d) suction bucket; (e) tripod foundation; (f) lattice (jacket) foundation; (g) floating foundation [16].

\section{Monopile Foundation}

Monopile (Figure 8c) is the most common foundation feature, used for shallow water, mainly lower than $30 \mathrm{~m}$. Its installation is very simple since there is no need for extra effort to drive the piles into the seabed. It is unclear as to what water depth monopile foundations become uneconomic. The monitoring of installed structures indicates that actual foundations offer greater stiffness than what is predicted by existing design methods; more accurate design methods are needed to reduce the weight and required embedment of monopile foundations. For seabed with clay, sand, or chalk stratigraphy, monopiles can be installed using impact hammers or vibratory driving. For a rocky seabed, drilling and boring pile methods are commonly adopted. Due to its ease of manufacture, low cost, and manageable construction, the monopile has been utilized worldwide for offshore wind turbine foundations.

\section{Tripod Foundations}

Tripod foundations (Figure 8e) comprise three medium-diameter steel pipe piles arranged in an equilateral triangle, the apex of which supports the upper tripod truss structure. As a precast unit, the tripod truss can bear upper loads applied to the tower and deliver stresses and moments to the three steel piles. The tripod foundation is stable, lightweight, and suitable for application in water depths of 10-35 m.

\section{Jacket (Lattice) Foundations}

The jacket foundation (Figure 8f) comprises a space frame structure assembled from steel tubular members, which is usually fabricated in advance by welding on land. The jacket is then transported to the site and piled into the seabed. Jacket foundations are relatively economical in terms of steel consumption, but storage, logistics, and installation can be expensive, substantially raising the overall cost. To date, jacket foundations have been widely used in intermediate water depths ranging from 5 to $50 \mathrm{~m}$. 


\section{Floating Foundations}

A floating foundation (Figure 8g) is a deeper sea substructure that aims to harness better wind resources further out in open sea. The floating foundation consists of a floating platform and an anchor system connecting to the seabed. A spar floater (Figure 9i), a single or multiple tension leg platform (Figure 9ii,iii), and a semi-submersible foundation (Figure 9iv) are the main types of offshore floating foundations, and these are based on the oil and gas industry. The floating foundation is mainly used in much deeper water that is greater than $50 \mathrm{~m}$ [52]; but in the offshore wind industry, the largest water depth of this foundation is about $100 \mathrm{~m}$, due to its characteristics.

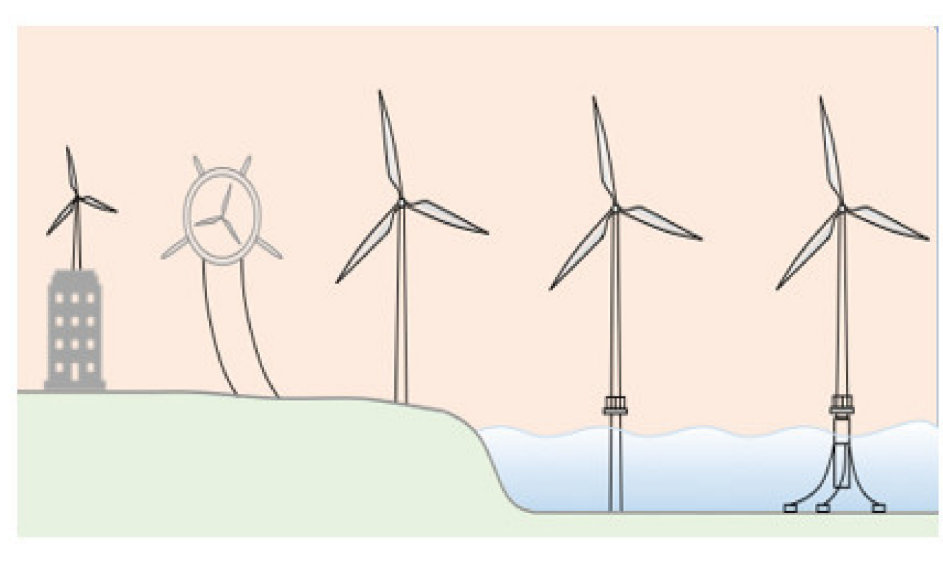

(a)

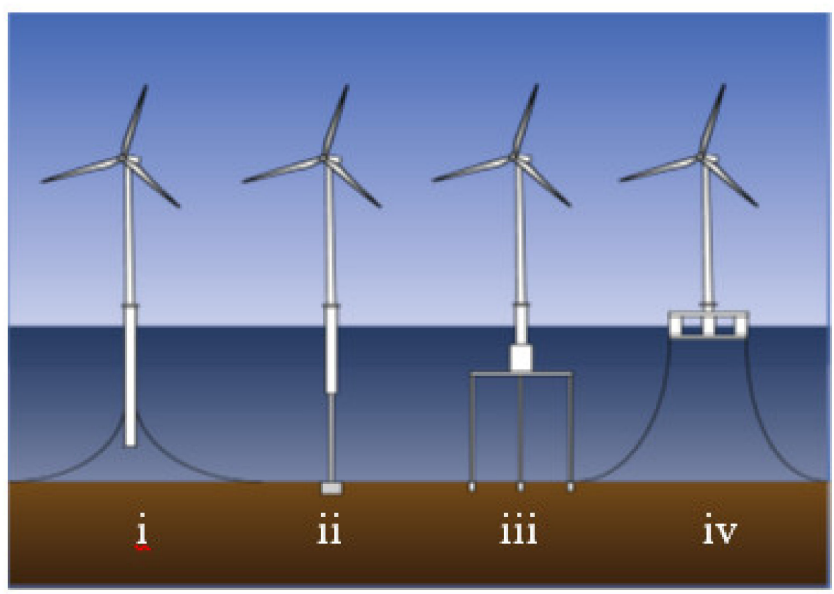

(b)

Figure 9. (a) Installation locations of wind energy converters with (b) floating foundations: (i) Spar floater; (ii) singletension-leg platform; (iii) multi-tension-leg platform; (iv) semi-submersible foundation [52].

\section{Suction Bucket Foundation}

A suction bucket foundation (Figure 8d) is an upside-down bucket insert into the seabed to provide resistance. This foundation has been used as the anchor of some offshore platforms, and is considered to be an efficient alternative to OWTs, which can conceptually cover a larger range of water depths, of 5-60 m, with a lower cost. The benefits of the suction bucket foundation include fast and low-noise installation, easy decommissioning, no seabed preparation needed, and adaptability to deeper waters as well as larger turbines.

Lastly, when offshore floating WTs are concerned, the stability of the floating platform is significantly affected by the mooring lines and the dynamic loads exerted. The floatertower system attains a much more complicated set of dynamic properties compared with fixed-bottom towers. Furthermore, it is crucial to consider the hysteretic behavior of the restoring forces of the mooring lines using reliable hysteretic models [53,54], which has been found to introduce noteworthy variations of the system response compared with quasi-static analyses [55].

\subsection{Connections}

Joints in tubular segments are vital for reliable structural performance and safe operation of the wind turbine. Flanges are used to connect all the segments and the whole tower to the foundation or the transition piece for onshore or offshore wind turbines, respectively [56]. The tower sections are welded with a seam lengthwise, as well as with circumferential welds to connect the next section. The flanges are also connected to the tower tubular sections with welds. A ring flange bolted connection is the most common type of joint and benefits from several advantages, such as low production costs and easy joint preparation. However, due to the eccentricities of the flange, an additional axial load is caused by reducing the maximum load and the fatigue performance [8]. Environmental 
conditions affect the bolted flange connection because of fatigue [57]. Bolts are sensitive due to self-loosening, fatigue failure, corrosion, and galling [58]. For offshore applications, large-diameter bolts with ultra-high strength, such as M72 and M64, are used. Protection against corrosion is achieved by hot-dip galvanizing; however, this diminishes the bolt's fatigue strength [59]. Braithwaite et al. studied the preload relaxation of an M72 bolt using Finite Element Analysis. They recorded a 5\% reduction of preload force for all initial load levels. This could lead to a lower load level, smaller than the minimum required after tightening [60]. The flange connection should be checked for its ultimate limit state and fatigue limit state. An analytical and numerical comparison indicated that the failure of the bolt and partial yielding of the shell is the primary mode of failure. In addition, fatigue damage takes place in the bolt shank near the bolt head, where the fatigue damage calculated by a numerical investigation was found to be $50 \%$ lower compared with the analytical one [61]. The flange is very susceptible to stress concentration. The weld connecting the shell part and the flange presents a high normal stress concentration. A comparative study of welds connecting tube sections and welds connecting the shell and the flange of a wind turbine verified the above assumption [62]. Alonso-Martinez et al., using finite element and experimental analysis, stated that the pretension of bolts resulted in a high stress concentration of the flange neck, which led to a collapse in Spain [63] (Figure 10).

Grouted connections (Figure 11) are a common connection type for offshore applications, connecting the transition piece with the monopile tower. The gap between the monopile and the substructure is filled with high-performance grout [64]. Their role is to safely transfer the load from the tower to the offshore foundation in the face of wind, wave, and rotor-nacelle assembly. However, they have not shown successful structural behavior as recorded in offshore wind farm installations, since unexpected settlements were observed [65]. Therefore, the access platform may reach the sea wave zone and the height of turbine height may be reduced, reducing energy production [66].

The dynamic loads transferred by grouted connections are applied to the top and bottom of the grouted assembly as several forces. Thus, an overturning moment may exist as a consequence of the sliding effect and the reduction of axial bearing capacity. Furthermore, slippage is recorded at the construction phase due to ovalization [67]. Moments acting on grout result in high tensile strength levels, inducing cracks in different directions [68]. It is common for constructors to avoid the inclusion of shear keys as a quicker and less costly configuration. However, this design feature is not recommended due to the reduction of long-term axial capacity [69]. Moreover, a conical shape of the grouted connection could be a promising solution, since it introduces a frictional mechanism, resisting slipping [70]. A grouted connection without shear keys was retrofitted using elastomeric bearings to carry the vertical loads on the monopile transition-piece area [71]. Tziavos et al., in their review, concluded that the design of offshore grouted foundations was based on the experience gained from offshore oil and gas structures [72]. The fatigue of grouted connections is also very important, especially for aggressive offshore environmental conditions [64].

A novel friction connection with open slotted holes has been proposed (Figure 12a) [73]. Bolts are pre-installed in the upper segment and slide in the top part of the lower section. The inner side of the shell has open slotted holes, where the width of the hole is equal to the normal clearance of the hole diameter. The outer shell provides the normal clearance holes of the side of the bolt heads. It has been found that the shell imperfection did not influence the structural performance of the friction connection [74]. Imperfections in ring flanges result in higher load levels of bolts, and redistribution of meridional membrane stresses on shell sections [75] (Figure 12c). Moreover, in a slip joint configuration (Figure 13), two identical parts fit into each other through overlapping without using bolts, grout, or welding. The connections depend only on the geometry and the counteracted load of the sections [66]. In the slip joint, the tensile and compressive forces of the tubular tower are transferred as friction forces. The slip joint remains on the elastic region during extreme load events; however, further research is needed considering economical and durability aspects [76]. 


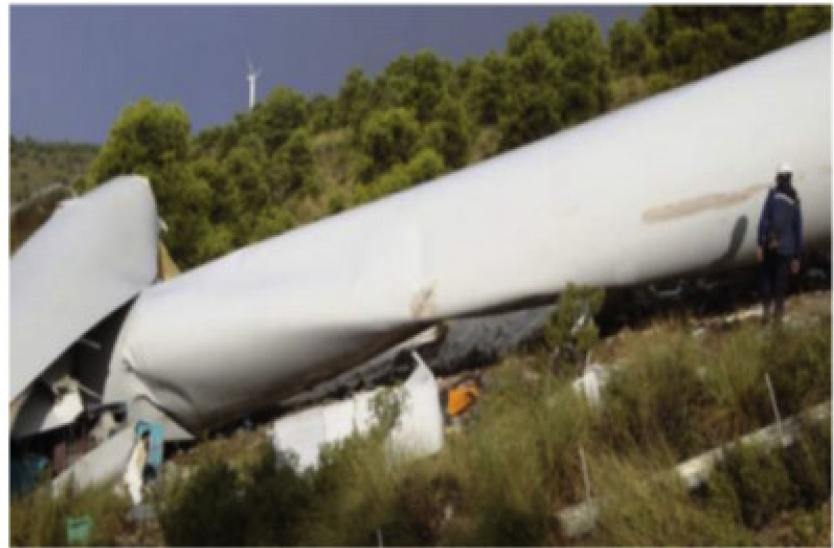

(a)

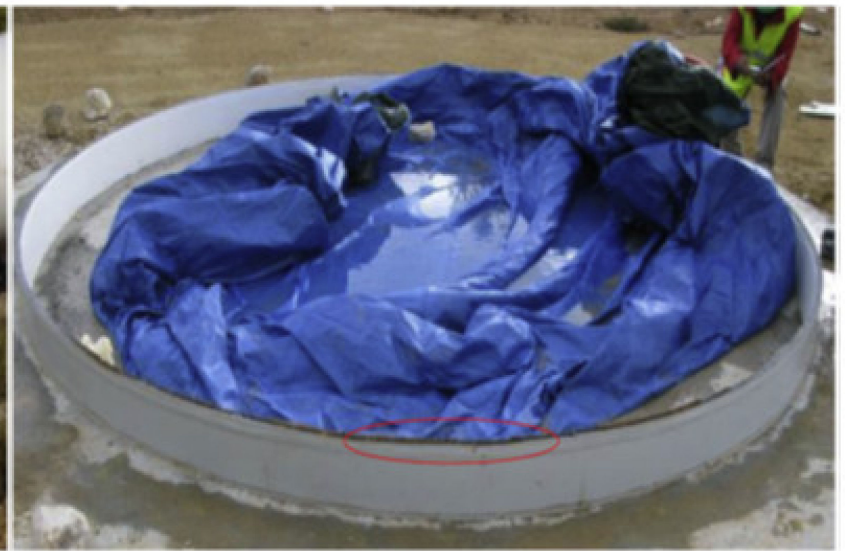

(b)

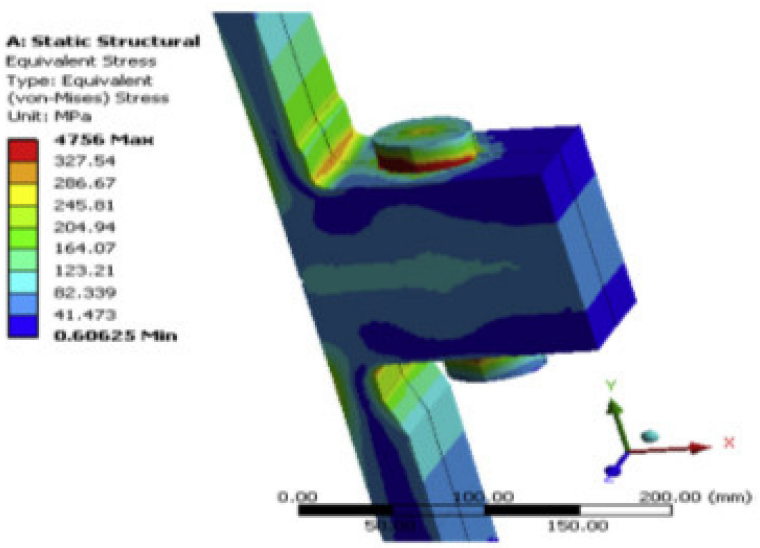

(c)

Figure 10. Wind turbine collapse due to flange failure. (a) View of the collapsed tower. (b) View of the flange after collapse. (c) FEM results. Von Misses stresses in flange [63].

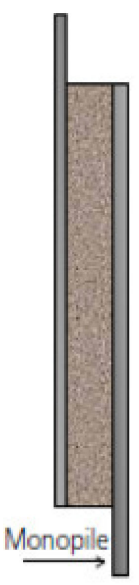

a)

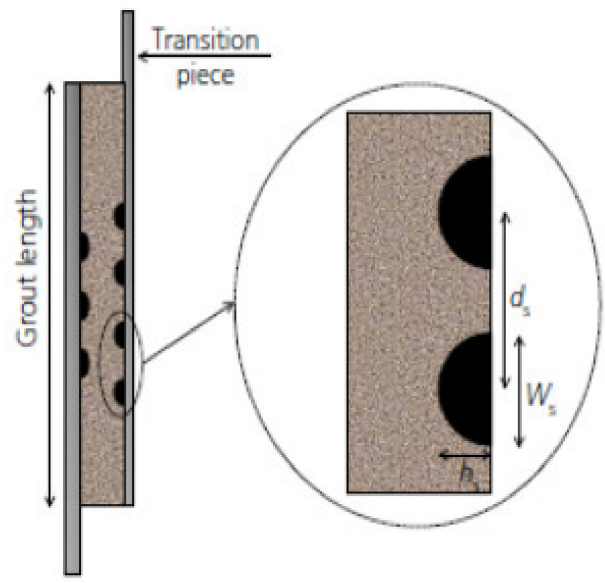

b)

Figure 11. Grouted connections without (a) and with (b) shear keys, where $d_{s}$ is the distance to center of shear keys, $\mathrm{W}_{\mathrm{s}}$ is the width, and $\mathrm{h}_{\mathrm{s}}$ is the height of the shear key. 

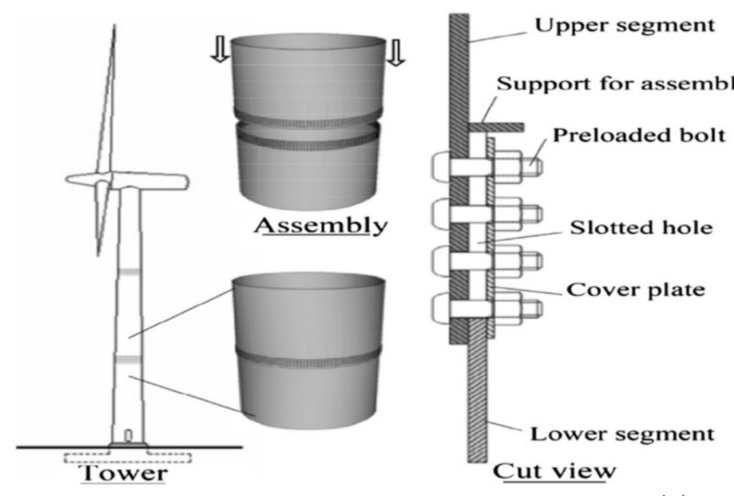

(a)
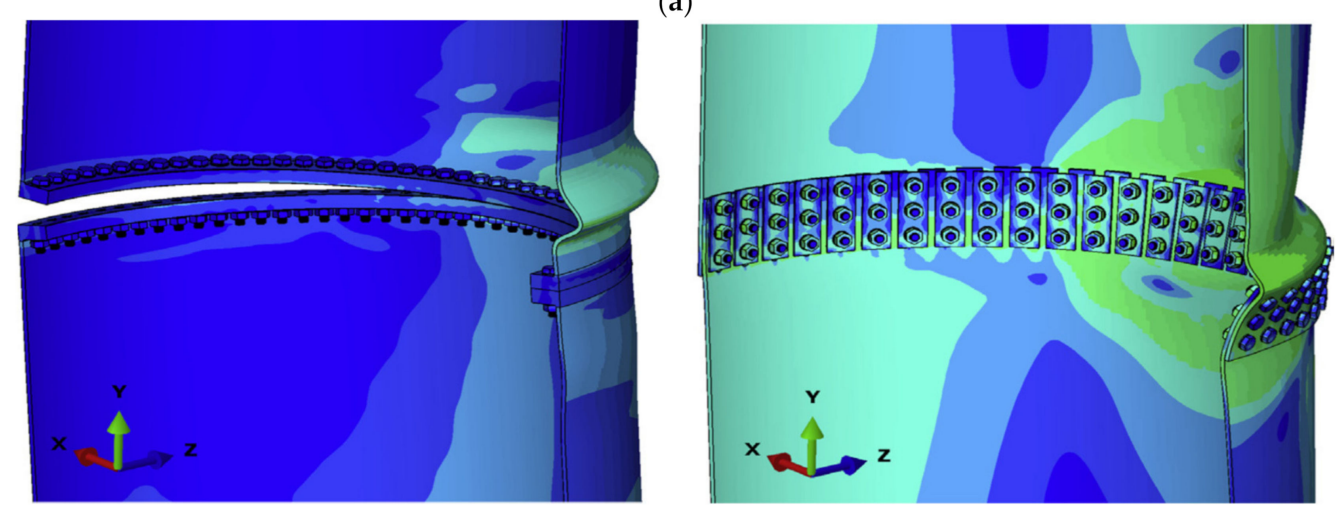

(b)
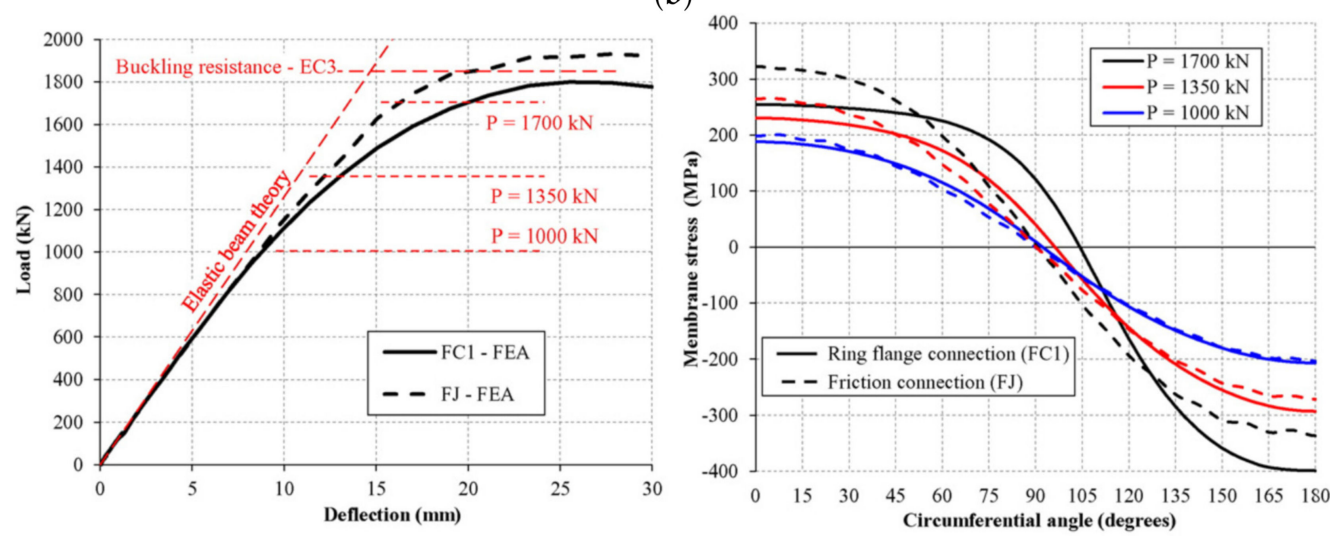

b) meridional stresses in the shell

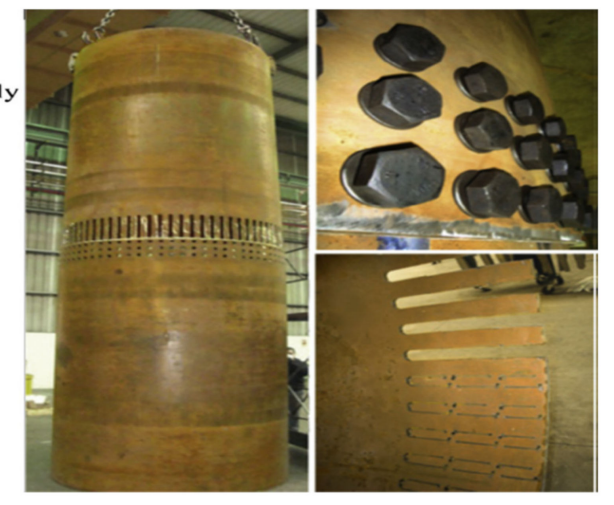

a) load-deflection curves

(c)

Figure 12. Friction connection. (a) Cut view and fabrication. (b) Comparative buckling analysis of ring flange and friction connection. (c) Comparison of structural behavior of ring flange and friction connection $[74,75]$.
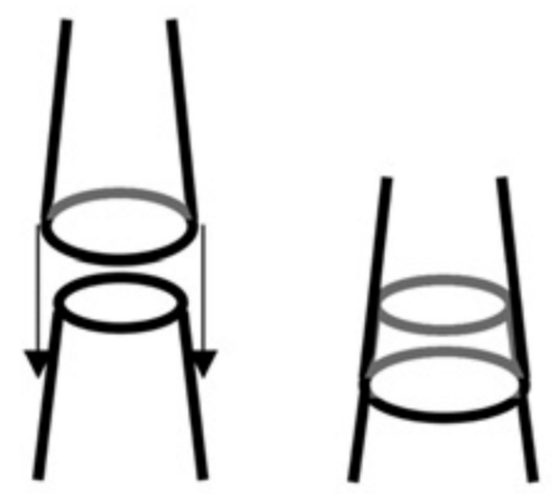

Figure 13. Slip joint configuration [76]. 


\section{Vibrations of Wind Turbine Towers}

\subsection{Multi-Hazard Assessment}

WTs are complex systems that need to withstand severe environmental conditions and thus the supporting tower should provide structural integrity to ensure continuous and unproblematic energy output during their lifetime. WTs are principally subjected to gravitational and dynamic forces. The self-weight of the tower and the weight of the nacelle and the rotor are considered the main static loads of the structure. More detailed analyses include the ice located in the nacelle, adding more stress for the tower. Dynamic external forces are much more important since they excite the vibration of the whole system. The common dynamic loads that an onshore tower is subjected to during its lifetime are the vibrations of the rotating blades at the top of the tower, the wind pressure, and more rarely, earthquakes. In the case of offshore wind turbine towers, the tower will be subjected to wave and current loads as well. The loads acting on a typical tower are shown in Figure 14.

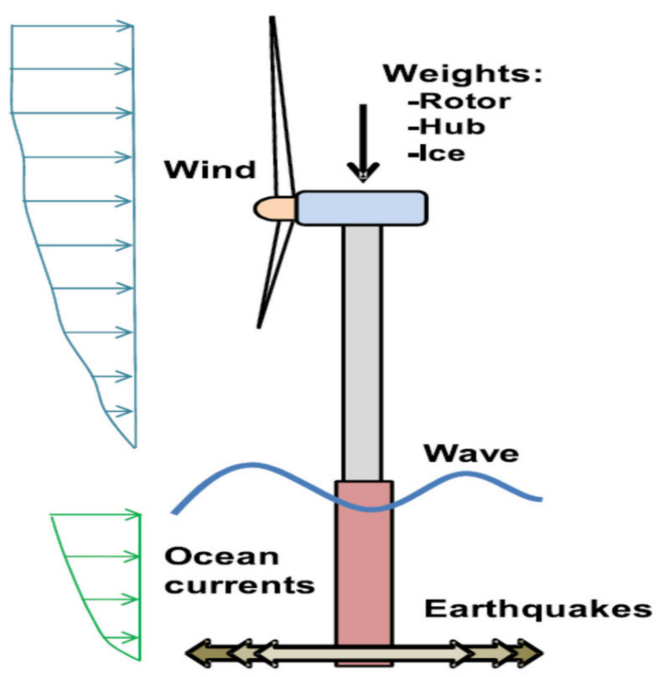

Figure 14. Typical loads acting on wind turbine towers [16].

The tower is the most important structural component of the system since it must transfer the loads safely to the foundation. Generally, the wind is considered as the primary load acting on the tower, with the wave and current loads affecting the structural performance of offshore applications as well. Extreme events, such as typhoons and hurricanes, are associated with severe damages and collapses. Extreme winds have been identified as the most common reason for the collapse of wind turbine towers. The tower suffers from buckling and stress concentration in areas where the thickness significantly changes [77]. Wind turbine towers are cantilever beams that lack redundancy and thus they cannot provide extensive force distribution. Excessive loads can lead to collapse when a single section reaches its yield strength. Then, the structure becomes a mechanism and thus the tower instantly collapses [78]. For this reason, WTTs are typically designed for larger safety factors against overloading [79].

Typhoons are the most common reason for wind turbine collapses. It has been noted that primary and secondary frequencies of typhoons are often close to the first modes of the structure [80]. Ishihara investigated the damage to wind turbines that collapsed during the Maemi Typhon. It was found that the maximum bending moment of the towers was greater than the ultimate bending moment, leading to buckling [81]. Li recorded five tower collapses because of typhoon Shaomai. One tower presented buckling issues at welded joints, two towers buckled at the middle of the base cylinder, and the last ones collapsed due to foundation failure [82]. Typhoon Usagi caused the collapse of eight steel tube towers. Buckling was observed $9-10 \mathrm{~m}$ above the ground in areas where the shell thickness decreased (Figure 15). Numerical investigations confirmed that this failure was traced back to areas that suffered stress concentration [83]. Finally, Chou investigated the 
collapse of wind turbine towers located in Tauchung, Taiwan. They combined the in situ investigation with the performance of a finite element analysis concluding that the pitch system was damaged, exposing the bolts to grater stresses leading to a failure [84].

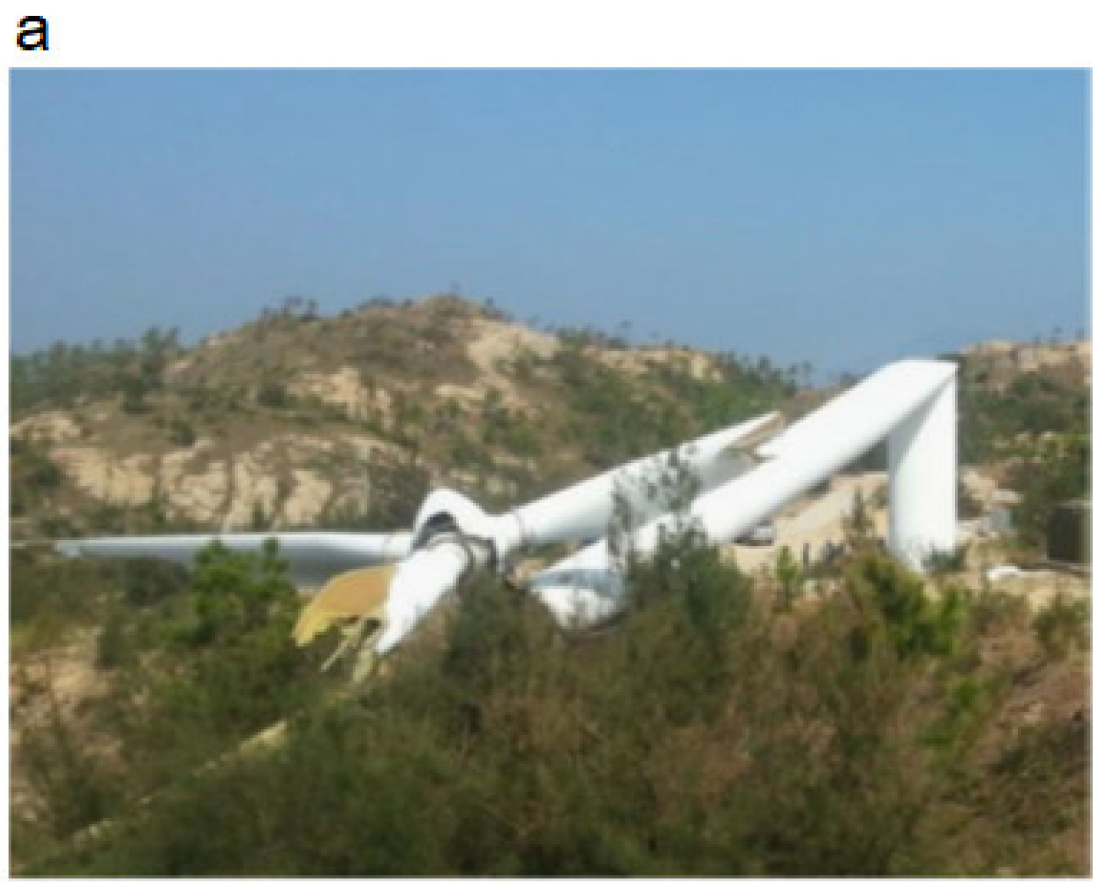

b

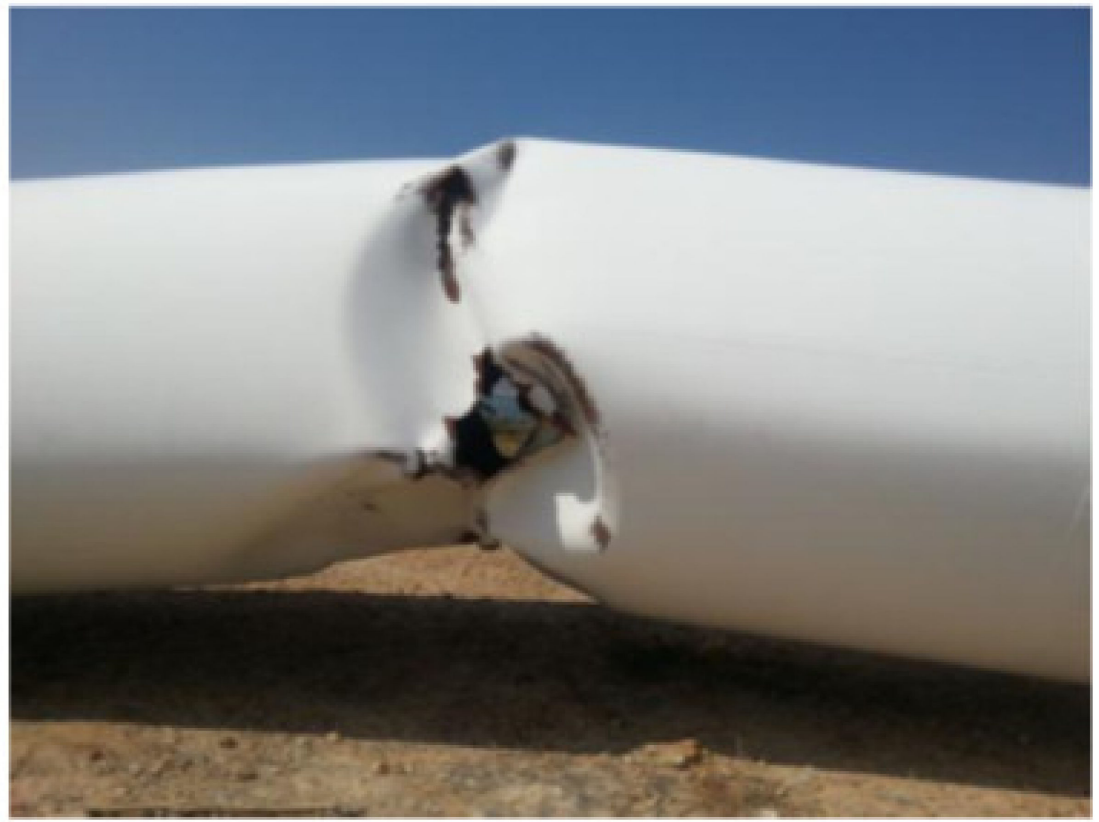

Figure 15. WT tower collapse due to typhoon Usagi. (a) Main view of the collapse. (b) Buckling failure of the tower [83].

Many wind farms are located in seismically sensitive areas. Therefore, strong ground motions provoked by earthquakes should be considered in combination with wind loads. The influence of seismic loads has been studied by many researchers. Bazeos used the Greek Seismic Code's response spectrum to study the seismic loads through pseudo-static analysis [21]. Lavassas et al. reported that the proportion of stresses due to seismic 
load was $60 \%$ in comparison with the respective stresses due to wind [20]. Guidelines suggest following the building codes in regard to the aseismic design. However, damping properties are significantly different. For common buildings, a $5 \%$ of damping ratio is assumed [85], whereas for wind turbine towers, different values for parked and operational conditions should be considered [86]. Stamatopoulos indicated that the damping ratio is estimated at approximately equal to or less than $1 \%$ due to the lack of aerodynamic damping. In addition, he pointed out that near-fault records may induce up to a 50\% increase in base shear and base moment forces compared with the respective values carried out in the elastic response spectrum [87]. Moreover, geometrical imperfections are found to reduce the spectral acceleration in which a plastic hinge occurs. Meanwhile, imperfections result in more possible hinge locations due to earthquakes [88]. The maximum response of the tower was noted in the case of operational conditions with the combined action of wind and strong ground motions. Operational frequencies may be matched with the prominent frequency of the ground motion, leading to the resonance of the whole system. Thus, Smith and Mahmoud suggested that an emergency shutdown may reduce the possibility of resonance [89]. The stages between yielding and full collapse were described by Zhao et al. First, yield occurs at the bottom part of the tower. As the load increases, the damage is observed in the welds connecting the flanges to the shell. A fully plastic hinge is developed once the entire perimeter of a section yields [78]. Asareh et al. performed a fragility analysis, defining damage measures related to the serviceability of the tower. Specifically, they defined a limit of $1.25 \%$ of the height of the tower and 5 degrees of rotation for maximum displacement and rotation, respectively. Maximum displacement represents an emergency shutdown whereas the rotation is related to the power efficiency and collision avoidance between the blades and the tower [90]. Lastly, fragility analysis carried out by Patil et al. showed that foundation overturning was the most critical performance-limiting state [91].

In addition to winds and earthquakes, offshore wind turbine towers suffer from wave and current loads. The wind-wave interaction has a major impact on the response of the tower. When the direction angle of the wind pressure is in line with the current pressure, the tower presents the maximum responses in terms of top displacement [92]. The main dynamic characteristics of wind-wave interactions are covered by the increment dynamic framework. The structural behavior can be determined either from wind or wave loads depending on structural features and local site conditions [93]. Obviously, in seismic regions, the combined action of wind, waves, and earthquakes should be considered for a reliable design. Greater peak ground increases the importance of ground motions on the structural response [94]. Zuo et al., investigated the structural response of offshore wind turbine towers subjected to earthquakes. They noticed that using onshore ground records as input underestimated the in- and out-of-plane responses. Furthermore, different inputs represent a more evident effect on operating wind turbines [95]. There are different ways to insert the ground motion. The nonlinear behavior of soil results in lower peak ground acceleration at the base of the offshore foundations [96]. A wind, wave, and earthquake risk assessment through fragility analysis was proposed by Mo et al., It was highlighted that the additional damping induced by wind due to the operation of the turbine reduced the overall response of the system in the case of small wind and wave loads; however, at a higher wind speed level, earthquakes lead to excessive top displacements [97].

\subsection{Vibration Analysis}

Modern tall wind turbine towers should avoid resonance due to its importance compared to other basic structural checks, such as buckling [98]. Resonance tends to increase the amplitude of the tower's displacement due to dynamic loads to which the tower is subjected. It has been found that controlling the structural vibration of a wind turbine tower may lead to a longer lifetime due to the decreases in the foundation and fatigue loads [99]. The dynamic structural behavior of WTTs is the most studied topic, focusing on natural frequencies, vibrations modes, resonance, and damping estimation [16]. Resonance 
is avoided by designing the tower's structural fundamental frequency to be far removed from the rotor frequency (1P) and the three-blade passing frequency (3P) [100]. There are three main dynamic designs in this respect, as shown in Figure 16 [101]:

- Soft-Soft tower, in which the fundamental frequency is less than the rotor blade.

- Soft-Stiff tower, where the frequency is in the region between the one-rotor-blade and three-blade passing frequency.

- Stiff-Stiff tower, where the fundamental frequency is greater than the three-blade rotor frequency.

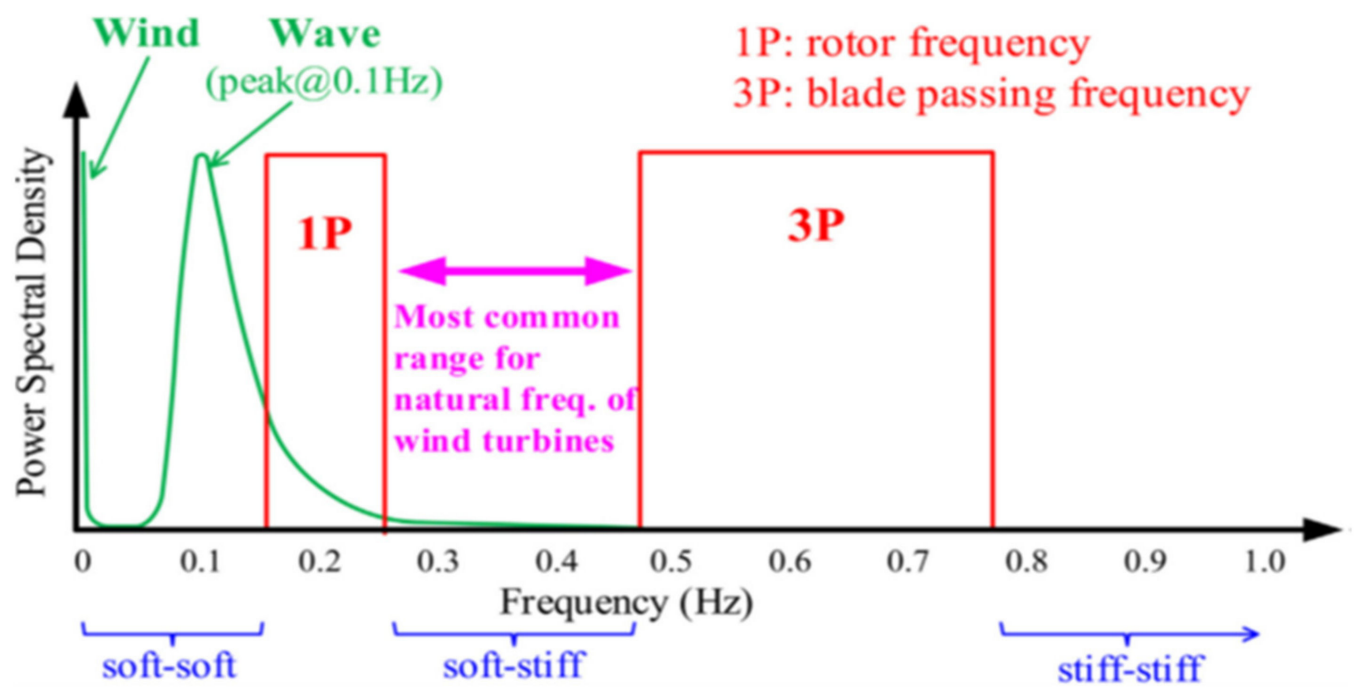

Figure 16. Frequency ranges of loads for wind turbines [102].

In the Germanischer Lloyd guidelines [103], $\mathrm{a} \pm 5 \%$ range for 1P and 3P frequencies is considered, whereas the DNV/Riso guidelines [104] define this range as $\pm 10 \%$. The soft-soft tower is the most economical design but is also susceptible to dynamic oscillations due to its flexibility. The stiff-stiff tower is less vulnerable to the external dynamic loads; however, cost increases significantly since stiffer design configurations mean larger crosssections and thus greater material consumption. Finally, the soft-stiff design leads to an economical and secure structure with an acceptable trade-off between construction cost and reliability [7]. Offshore wind turbines are mainly designed as soft-stiff structures, typically in a range of $0.3 \mathrm{~Hz}$ and $1 \mathrm{~Hz}$ for the rotor rotation and blade passing, respectively [105]. In addition, the spectral region covered by wind and wave loads is typically around frequencies below the 1P frequency, as it is shown in Figure 16 [106].

Plenty of research has been conducted to assess the dynamic behavior of wind turbines under a variety of conditions. Modal resonance is a major factor for the overall performance of the plant, and with the increasing size of wind turbines, dynamic analysis becomes even more significant. Wang et al. investigated the influence of piled foundations on the resonant characteristics of onshore wind turbines, concluding that piled foundations increase the frequency of the whole structure compared to shallow foundations [100]. Hu et al., examined the dynamic response of an offshore wind turbine during its erection phase, finding that wind-wave current loads has a major impact on the dynamic response of the structure [92]. Corciulo et al., estimated the natural frequency of offshore wind turbines considering the linear and nonlinear behavior of the sand at different wind speeds [107].

Foundation models considering multiple design features were studied by Zaaijer, concluding that there is a high percentage of uncertainty in regards to the gravity base structure [108]. For monopile foundations, the fixed-base assumption may overestimate the natural frequency by roughly $15 \%$, indicating that the foundation should be included in the overall analysis [109]. When the Soil-Structure Interaction (SSI) is considered, the eigenfrequencies are decreased in the case of wind turbine towers with foundations in 
soft soils, leading to a more flexible structure and increasing the displacement [110]. The dynamic properties of the tower are dependent on the shear strength and the strain of the soil. More specifically, the natural frequencies increase as the shear strength increases. On the contrary, an increase in soil strain leads to lower frequencies [94]. Ali et al., suggests that rotor nacelle assembly should be included in the analysis since the rotary inertia of the blades and the eccentricity of the rotor lengthens the natural period of the tower [111]. The effect of scour was also studied, showing that there is a difference of around $8.5 \%$ in the resonance vibrations of offshore wind turbines with foundations in loose sands [112].

\section{Vibration Control Methods}

Wind turbine towers are usually installed in hostile environments, and they should provide stability for the turbine. Several vibration control methods have been proposed to reduce the oscillations of the tower and the energy production of the wind turbine. Three basic control schemes have been applied: Passive, active, and semi-active. A passive controller does not need external resources-mainly power-for its operation, resorting to the configuration of the system at the design stage to enact effective mitigation of the tower's vibrating response to loading. On the contrary, active methods require external power for the actuation of the damper, controlled by complex algorithms. The semi-active technique is a compromise that requires considerably less external power than the active one to reconfigure the properties of the damper after deployment of the tower, mainly focusing on its tuning point and the instantaneous damping ratio [113].

\subsection{Passive Control Methods}

Passive control methods provide simplicity since they can mitigate the wind turbine vibrations without requiring an external power supply. There is a range of different passive configurations, such as Tuned Mass Dampers (TMDs), Tuned Liquid Dampers (TLDs), and Tuned Liquid Columns Dampers (TLCDs), which have mostly been studied to mitigate the vibration issues of wind turbine towers, for both offshore and onshore installations.

\subsubsection{Tuned Mass Dampers (TMDs)}

TMDs consist of a mass, a dashpot, and a spring. The dashpot and the spring reflect the damping ratio and the additional stiffness, respectively. TMDs are linear oscillators that are attached to a primary system (the tower herein) to alter the modal content of the ensuing oscillating system by design. Assuming the tower's fundamental mode as a Single Degree of Freedom (SDOF) system, the TMD is connected to the tower through the spring and damper as it is shown in Figure 17. The goal of using such a feature is to achieve out-of-phase resonance between the TMD and the wind turbine tower. In that way, large amounts of energy are dissipated by the TMD's damper with the primary system performing low-amplitude oscillations. A single TMD is usually placed at the top of the tower to deal with the large amplitudes of displacements that occur at the nacelle due to the shape of the first cantilever mode of the tower. Murtagh et al., compared the response of a wind turbine tower with and without TMD at the top of the tower with regards to the time-domain fore-aft displacement due to wind loads. After achieving the optimal tuning ratio for the fundamental frequency of the wind turbine tower, a significant reduction of the tower's response amplitude was observed [114]. The orientation of the rotor hub is a significant factor in the design of TMDs since it induces a significant band gap between their respective frequencies and variation in the aerodynamic damping ratio. Tong et al., installed two independent TMDs at the nacelle to control the side-side and fore-aft vibrations, which inevitably lead to increased demand for the additional weight and space. The authors reported substantial fatigue load reduction for both directions, particularly for side-side vibrations, reaching up to $68.7 \%$ [115]. 


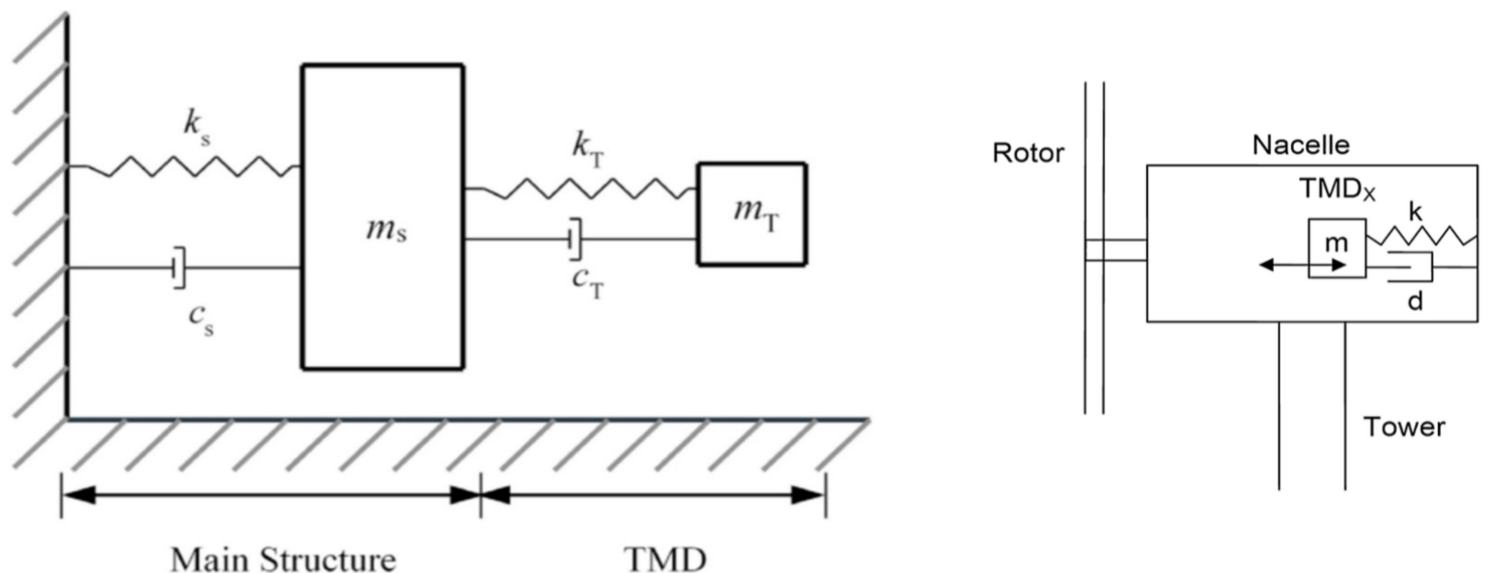

Figure 17. A schematic view of TMD [116].

TMDs are gaining much interest, especially in offshore wind turbine structures, since they can significantly reduce the response of the tower due to wind-wave loads and, occasionally, seismic loads, whereas they can improve the stability of floaters. The installation of TMDs on spar platforms showed that they are more efficient on the upper side of the spar platform [117]. The effect of TMDs on the most common floaters for offshore wind turbines was investigated by Stewart et al. [118]. A comparison between TMDs located at the top of the tower and on the platform was considered. For a barge wind turbine, it was found that the TMD is more effective when it is placed on the platform. On the contrary, studying the spar wind turbine, putting the TMD at the top is more effective since the ultimate and the fatigue loads were reduced. Lastly, in the case of tension leg platforms, the TMD in the nacelle showed better performance due to the decrease in mooring-line loads. Overall, the authors reported that fatigue damage was reduced by up to $20 \%$.

Jahangiri and Sun proposed a 3D-Pendulum TMD (Figure 18a) to be tuned to the dominant fore-aft natural frequency of a spar offshore WT [119] combined with pounding TMDs on the spar, extending their previous work on 3D pendulum TMDs for WTs [120]. Pendulum TMDs take advantage of gravitational forces to tune the pendulum to the target frequency. Although the size of the required pendulum to achieve tuning at the low frequencies observed in the sea could be excessive, it has been suggested that the height of tall towers could possibly accommodate them. In the work by Jahangiri and Sun, an optimal design of a $0.1 \%$ mass ratio with respect to the total mass of the WT and the spar reduced the rotational motion of the spar (RMS) in the fore-aft direction by roughly $32 \%$ [119]. The authors proposed a spherical pendulum with the premise of counteracting both fore-aft and side-side vibrations with a single device (Figure 18b). Although the foreaft frequency was attenuated as it is observed in the time history and the response spectrum of the wind-wave loading scenario (Figure 19a,c), the response to the narrowband wave excitation was completely unaffected, maintaining a considerable vibrational load. On the other hand, the side-side vibration spectrum shows attenuation of the resonance frequency; however, the wave excitation is clearly more important, dominating the response spectrum (Figure 19d) and thus leading the controlled response time history to be almost identical to that of the uncontrolled response. This effectively indicates a marginal contribution to the mitigation of the side-side vibrations. Furthermore, the spar response in all examined directions demonstrated favorable performance with the displacement reduction in a range of $18 \%$ to $50 \%$, attributed to the action of the pounding TMDs (Figure 18c) However, as it was noted before, this is evaluated based on the average response spectrum, which is dominated by the steady-state response. Again, the control was incapable of modifying the transient dynamics of the spar, which may play a significant role in the multi-hazard assessment of the WT. 


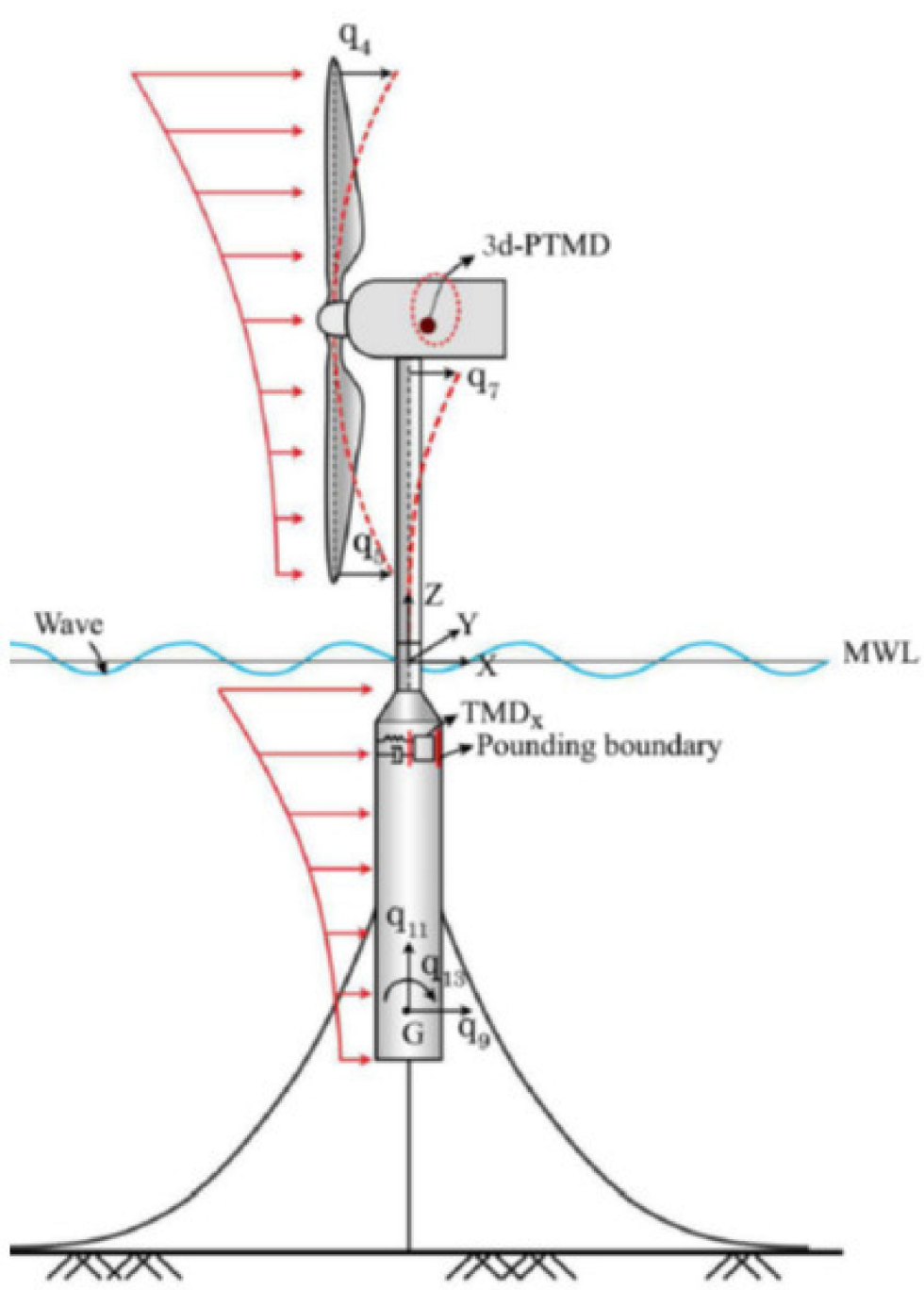

(a)

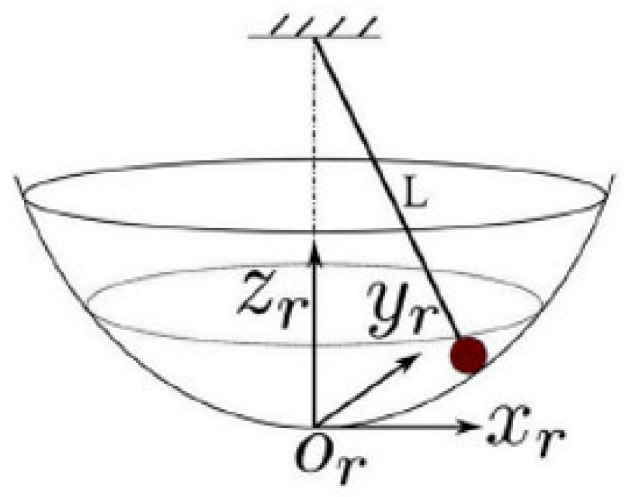

(b)

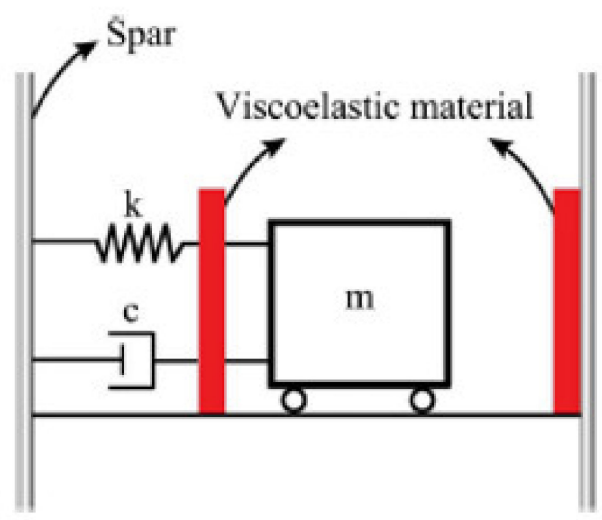

(c)

Figure 18. 3D pendulum TMD combined with pounding TMD at the spar. (a) Sketch of the spar WT with the pendulum located in the nacelle and the pounding TMDs at the top of the spar; (b) action space of the spherical pendulum; (c) sketch of the pounding TMD [119].

In the case of a wind turbine located at seismic regions, earthquakes may be another vibration source, which is particularly problematic for offshore installations since the frequency content of strong ground motion is very different from the respective wind and waves. Earthquakes mainly resonate with the second vibration mode of the wind turbine tower and therefore the maximum displacement will be observed at different heights of the tower corresponding to the peak values of the respective excited modes. It has been found that multiple TMDs located at points of large modal amplitudes provide promising results for load mitigation when a wind turbine tower is subjected to the combined wind-waveearthquake loads [121]. Moreover, the soil-structure interaction should not be ignored in the efficient design of TMDs, since the flexibility of the soil could decrease the frequency of the structure by up to $25 \%$ [122,123]. Even though a TMD system is relatively simple, its untoward operation is very possible with a combination of multiple dampers, influencing the effectiveness of the control process. Chen investigated the robustness of the MTMD system, concluding that despite the decreased control efficiency when some TMDs are not working at their optimal point, the structural response is still better compared to the uncontrolled scheme [124]. Nevertheless, this recent work highlights some of the central 
issues with TMDs. The jacket foundation WT was subjected to wind and current loads from a rest position, which is clearly not a realistic scenario. Yet, very illuminating conclusions can be made from the presented FEA results. The steady-state response of the structure does indeed show a reduction in the passively controlled amplitude of the nacelle when the TMD mass ratio is sufficient (Figure 20). However, the transient response from the rest position shows nearly identical peak displacement and acceleration as the uncontrolled system, which effectively alludes to the incapacitation of the TMDs when fast transient dynamics are excited. The latter is a pressing issue for offshore installations in particular, where multiple random environmental loads could excite the structure to intermittently large response with unpredicted consequences for the fatigue of the structure or other potential damage such as local buckling.
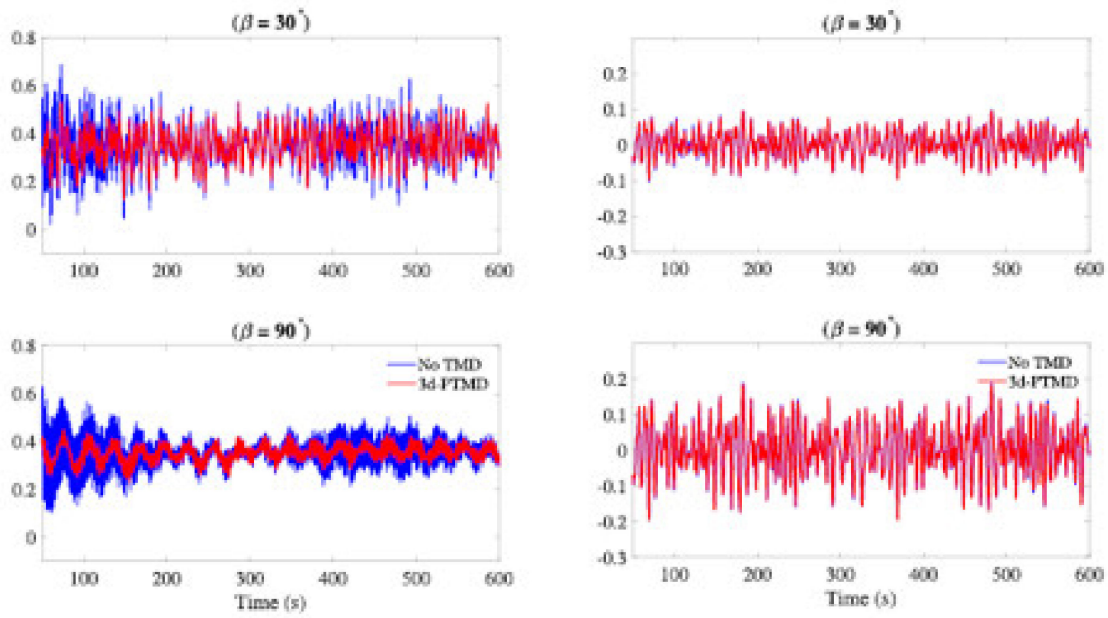

(a)

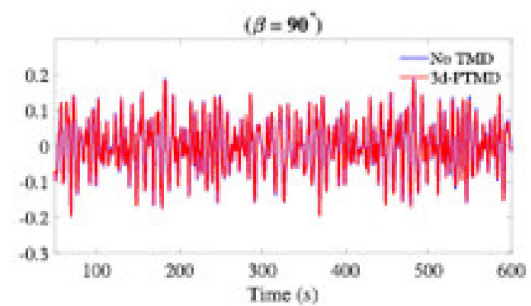

(b)

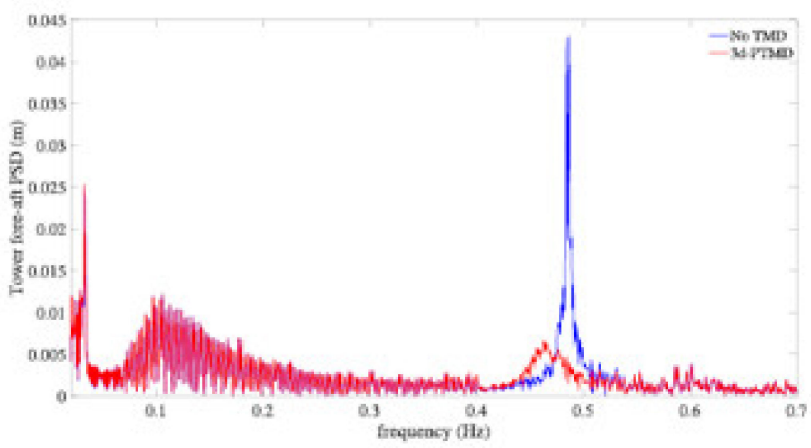

(c)

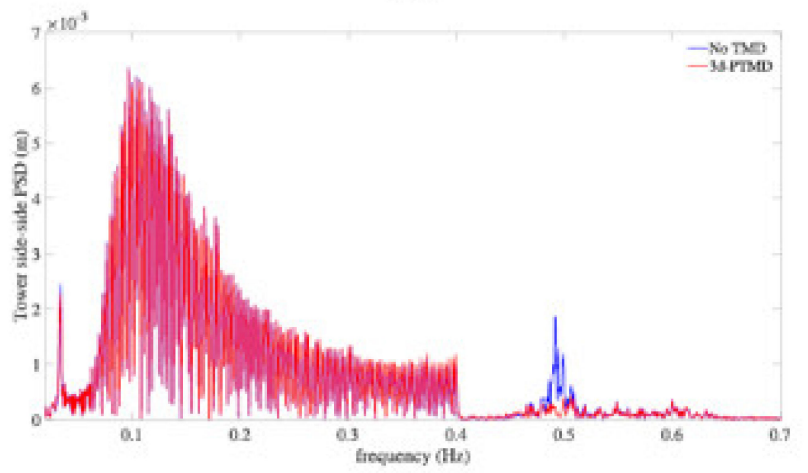

(d)

Figure 19. Nacelle response to combined wind-wave excitation with and without the 3D pendulum damper. (a) Time history in the fore-aft direction; (b) side-side vibration time history; (c) fore-aft response spectrum; (d) side-side response spectrum [119]. 


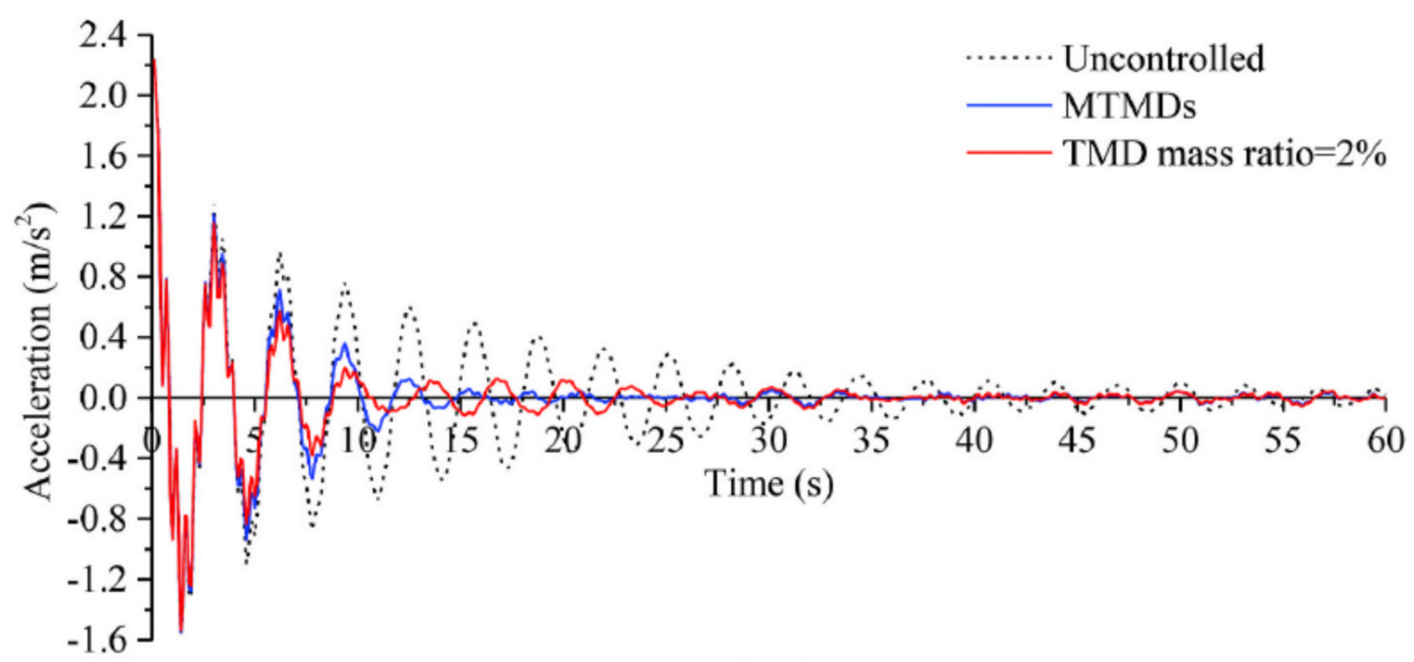

Figure 20. Acceleration time history of the top of the tower for MTMD compared with a single TMD and the uncontrolled system (Chen et al., 2021a).

Interestingly, Leng et al. showed that excessive vibration amplitudes were induced by TMDs in scenarios of partial stiffness loss (e.g., damage) under combined wind-waveearthquake loading of a jacket offshore WT [125]. In fact, the authors considered a 5\% reduction in stiffness, revealing an increase in RMS displacement compared to the uncontrolled case of $33.97 \%, 30.16 \%$, and $17.88 \%$ when the damage was initiated before, during, and after the earthquake, respectively. The typical double-peaked TMD-controlled spectrum is evident in Figure 21, which shows that both broadband and narrowband vibrations are excited, leading to a diminished RMS time history.

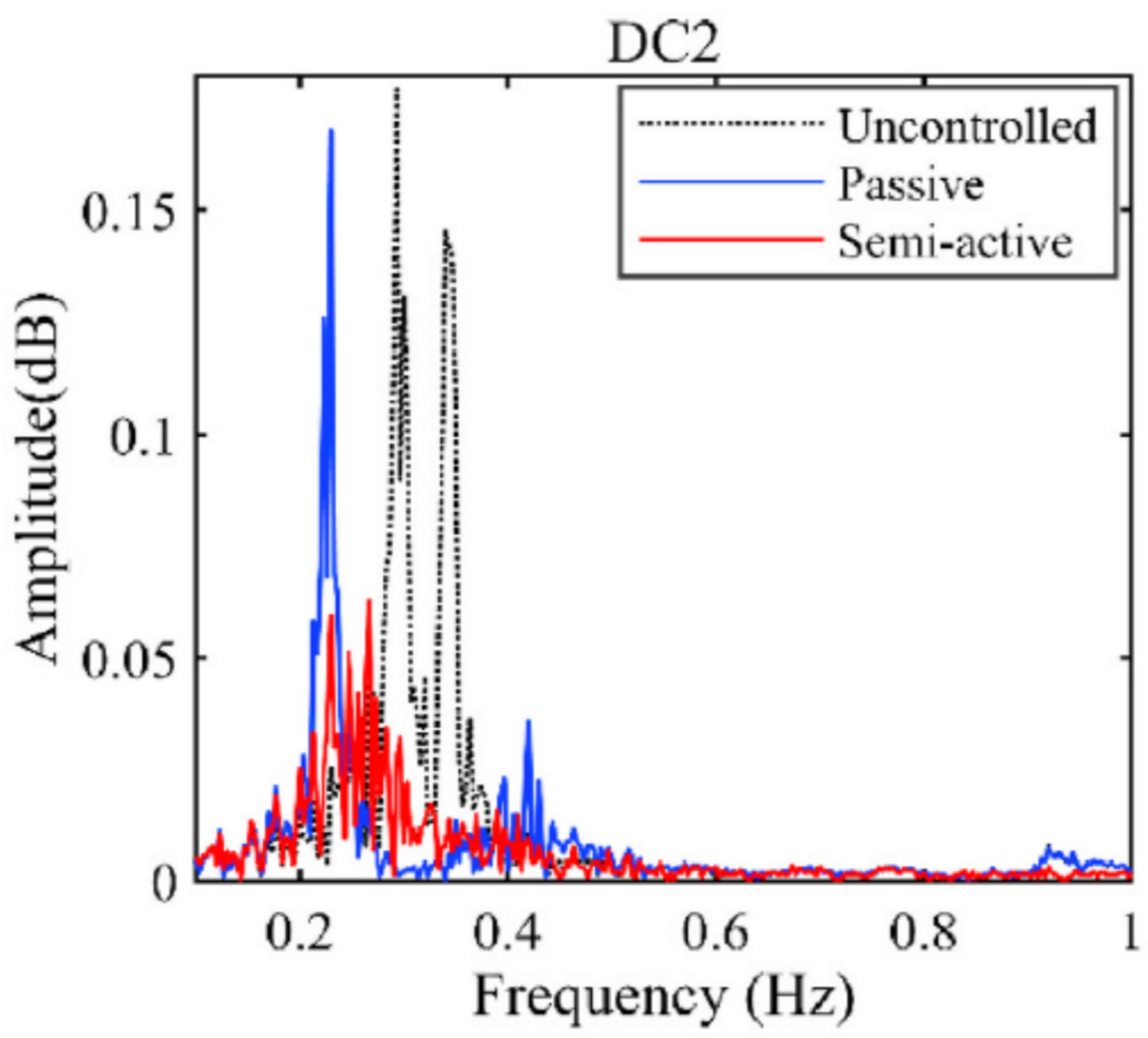

Figure 21. Response spectrum of the tower with developing damage [125]. 
Despite their promising performance enhancement, the above observations reveal two main issues that limit the potential of TMDs to control the vibrations of WT towers. Firstly, the successful mitigation of vibrations is highly dependent on the tuning frequency of the TMD. In fact, TMDs modify the frequency response of the primary system such that the structure's response is minimized at a particular target frequency, normally the structure's resonant frequency. Potential detuning of the TMD either due to malfunction of the TMD or a mild variation of the structure's properties may not only negatively affect the control performance, but it could give rise to previously unexcited resonances, which could be catastrophic in an environment with broad spectral excitations. Besides, the design of TMDs originates from harmonic analysis, which may be insufficient for the combination of multiple random loads and more prominent nonlinear characteristics of the relevant structural systems resulting from lightweight designs. In addition, besides the considerable added weight at the nacelle, the installation of a TMD at the top of the tower introduces feasibility difficulties because of the limited space for the nacelle and the TMD stroke that is necessary to favorably control the vibrations of the tower [113]. The latter is also an issue for alternative realizations of TMDs rather than the use of elastic forces to control the structure's vibrations (e.g., tuned rolling ball [126]). Nevertheless, recent work on structural vibration control is focused on overcoming these issues, such as the development of tuned mass eddy current dampers [127], for which initial work has shown promising results.

\subsubsection{Tuned Liquid Damper}

An extension of the dynamics governing the TMD is the Tuned Liquid Damper (TLD). The TLD consists of a commonly rectangular or circular tank that is partially filled with water (Figure 22). The sloshing frequency of the liquid is designed to be equal to the fundamental frequency of the structure that the TLD is intended to control. When the tower is forced to vibrate due to external loads, the liquid sloshes within the container, exerting an inertial force on the main structure. It has been reported that TLDs are a cost-effective and simple damping configuration [113], providing a low initial cost, low maintenance needs, and relatively easy tuning [116].
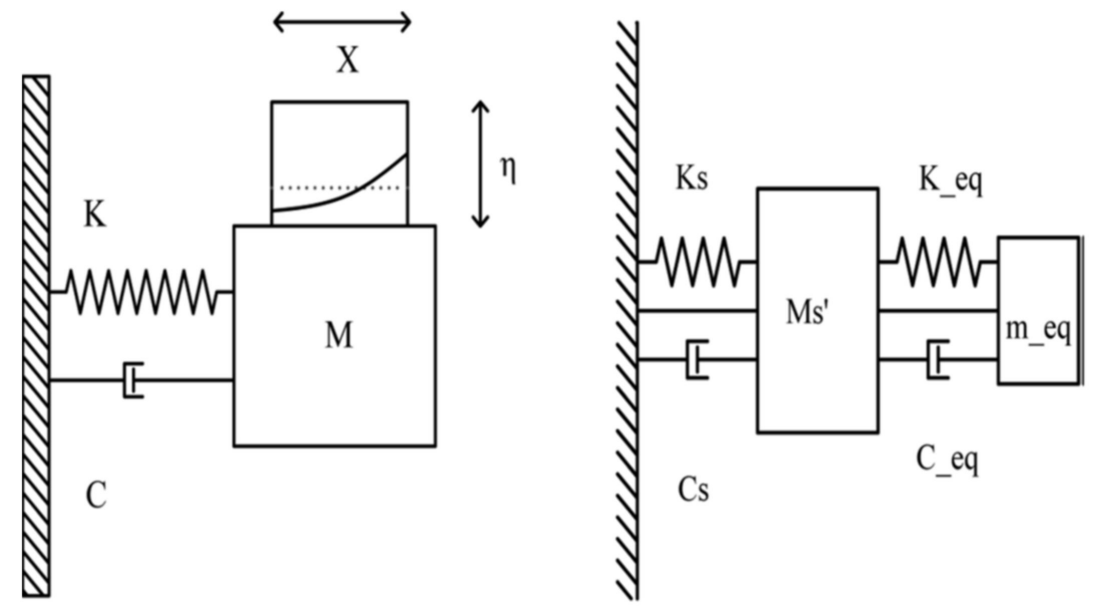

Figure 22. Schematic view of TLD (Xie and Aly, 2020).

TLDs' reliability depends on the motion of the liquid inside the tank due to its nonlinear nature since it makes their design and modelling challenging. In order to overcome the requirement of rectangular or cylindrical TLD tanks for large installation space, Ghaemmaghami et al. proposed an annular TLD (Figure 23). After examining its efficiency, they concluded that an optimum mass ratio (5\% mass ratio) results in a $69 \%$ decrease in the response of the wind turbine tower under wind loads only. Moreover, high amplitudes of wind load lead to lower effective damping ratios [128]. A multi-layer TLD was proposed by $\mathrm{Ha}$ and Cheong for a floating wind turbine (Figure 24). The single-layer concept reduced 
the pitch motion by around 5\% in contrast to the five-layer TLD concept in which the respective reduction was estimated at around 23\% [129]. Zhang et al. used real-time hybrid aeroelastic simulations in a wind turbine tower using damping screens to evaluate the performance of TLDs. They concluded that the damping screens increased the energy dissipation during liquid sloshing [130]. Furthermore, using a sloped bottom in the tank, they achieved a more efficient TLD with less liquid [131].

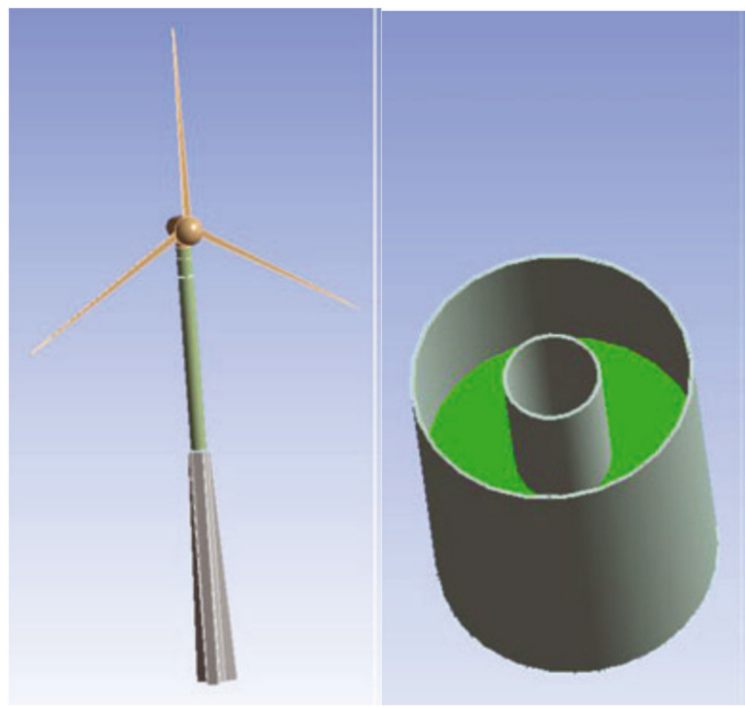

Figure 23. Annular TLD installed in hybrid concrete-steel tower [128].
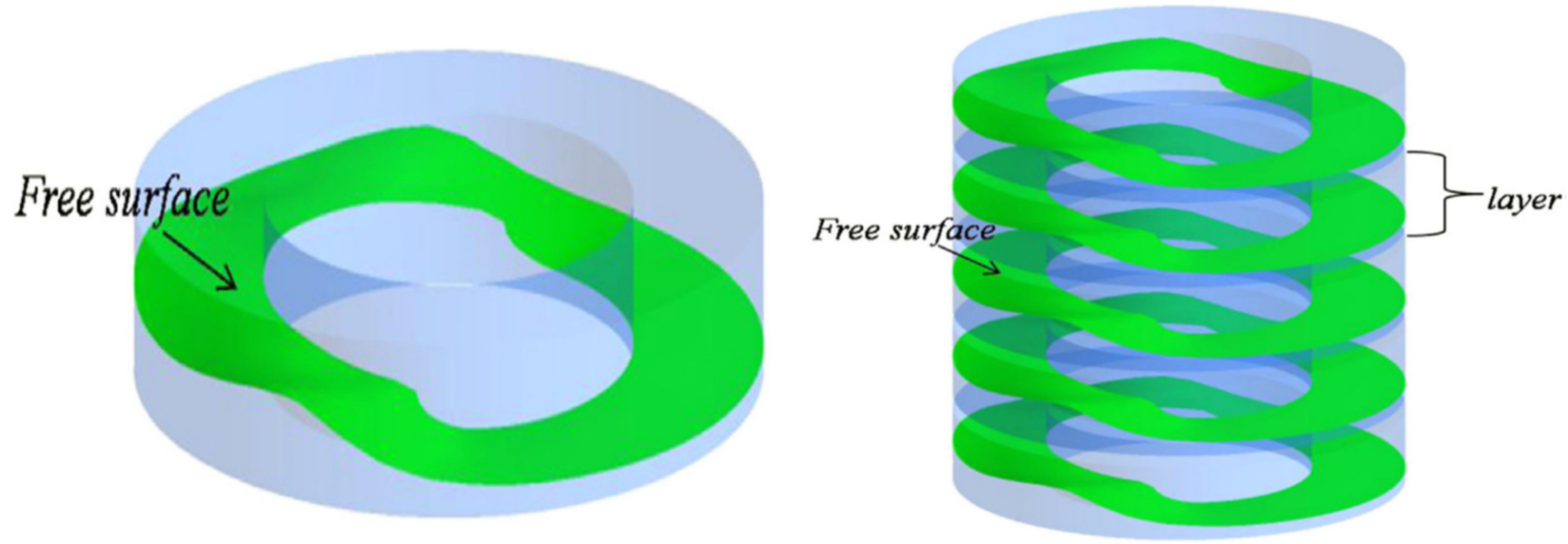

Figure 24. Single and multi-layer TLD [129].

Several studies have shown TLDs can efficiently reduce tower vibrations; however, liquid sloshing is a highly nonlinear problem, which makes it difficult to accurately design the frequency of TLDs for the varying frequencies and amplitudes of the environmental excitations that a WTT may be subject to. A novel contribution by Ruiz et. al., concerned the addition of a floating roof to linearize the operation of the damper even for large amplitudes [132]; however, the damping ratio remains hardly controllable, which might lead to sub-optimal performance. Besides, it has been reported that the stabilization of offshore floating WTs with tuned liquids requires extensive modifications [133].

\subsubsection{Tuned Liquid Column Damper}

A technical upgrade of the main components involved in TLDs is the conception of Tuned Liquid Column Dampers (TLCD). TLCDs primarily consist of vertical liquid columns that are connected at their bottom end, forming a U-shaped container. The container liquid 
can move back and forth among the vertical columns of the container through an orifice that is usually placed in the horizontal connecting column as it is schematically shown in Figure 25. The container is placed on the primary vibrating system such that vibrations of the structure transfer kinetic energy to the liquid. The main difference compared to TLDs is the presence of the orifice, which is the primary source of damping, providing better control of the damping ratio and higher damping efficiency. A significant technical advantage of TLCDs when compared with TMDs is the reduced space required for installation in structures [134].

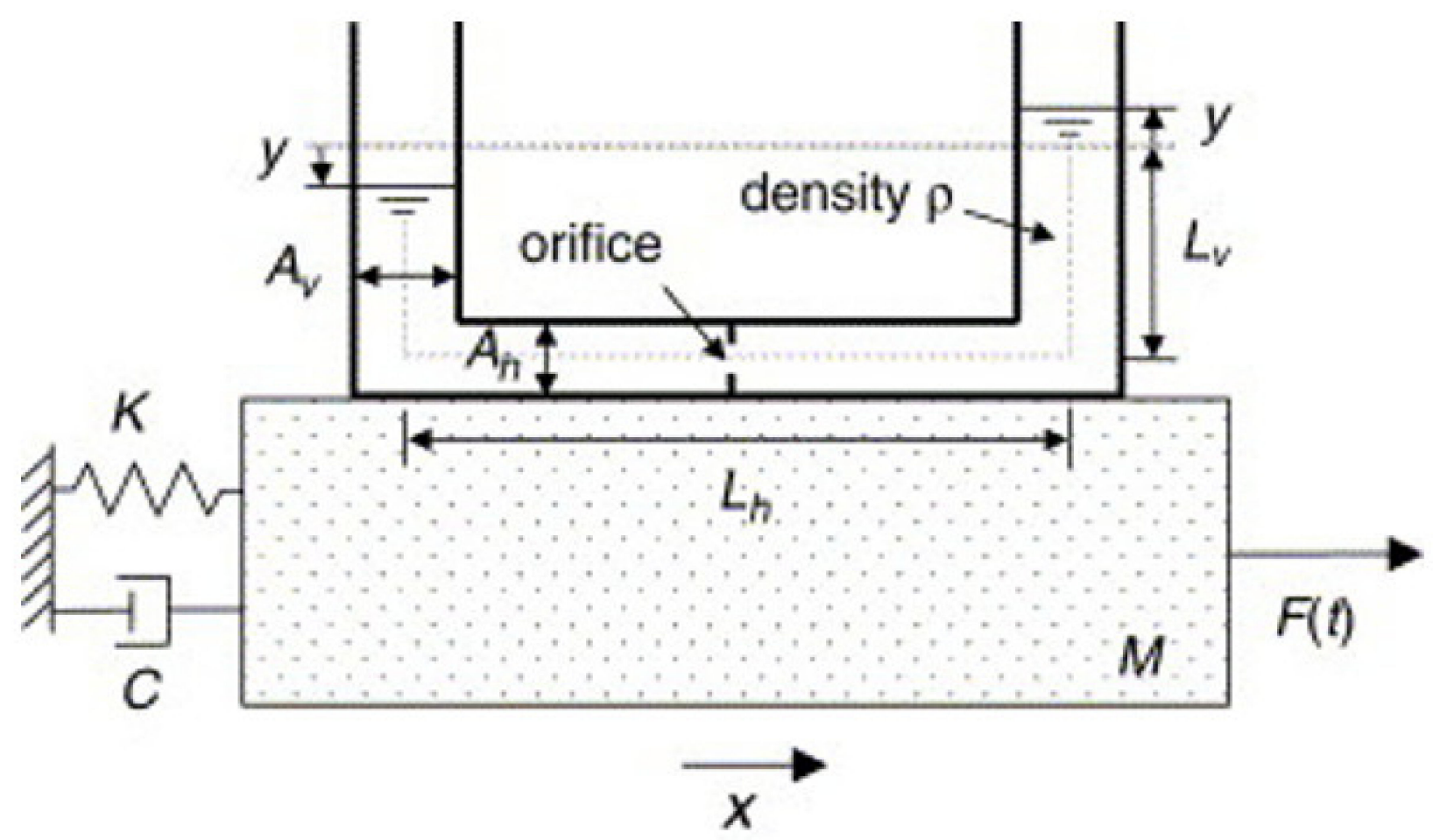

Figure 25. Schematic view of a TLCD [135].

TLCDs take advantage of the low cost of installation and maintenance, similarly to TLDs. In an early study, a TLCD was found to ease the response of an offshore wind turbine tower by up to $55 \%$, increasing the fatigue resistance as well [136]. Furthermore, in terms of fragility curves, the wind TLCD decreases the possibility of serious damage stages. However, using multiple TLCDs, no additional improvement in the structure's response was observed [137]. Moreover, a study considering the combined effect of a TLCD and a TMD installed on the nacelle was carried out by Hemmati et al. [138]. They concluded that the TMD presents better performance at operational conditions and the TLCD at parked conditions, and the combined action increases the overall performance against fatigue, which prolongs the lifetime of the wind turbine. Chen et al. conducted a shaking table test (Figure 26) of a 1/13-scaled model of an offshore monopile WT simulating combined wind and wave loading with equivalent ground accelerograms. The experimental results under four input accelerograms were found to be in agreement with finite element simulations for parked and operational conditions of 4.8 and $12 \mathrm{rpm}$. Although the TLCD showed a reduction of the peak displacement in the fore-aft direction for all considered cases, the authors allude to the problem of adopting sample-based deterministic methods to design and evaluate control methods for the structural response to stochastic environmental loads [139]. 


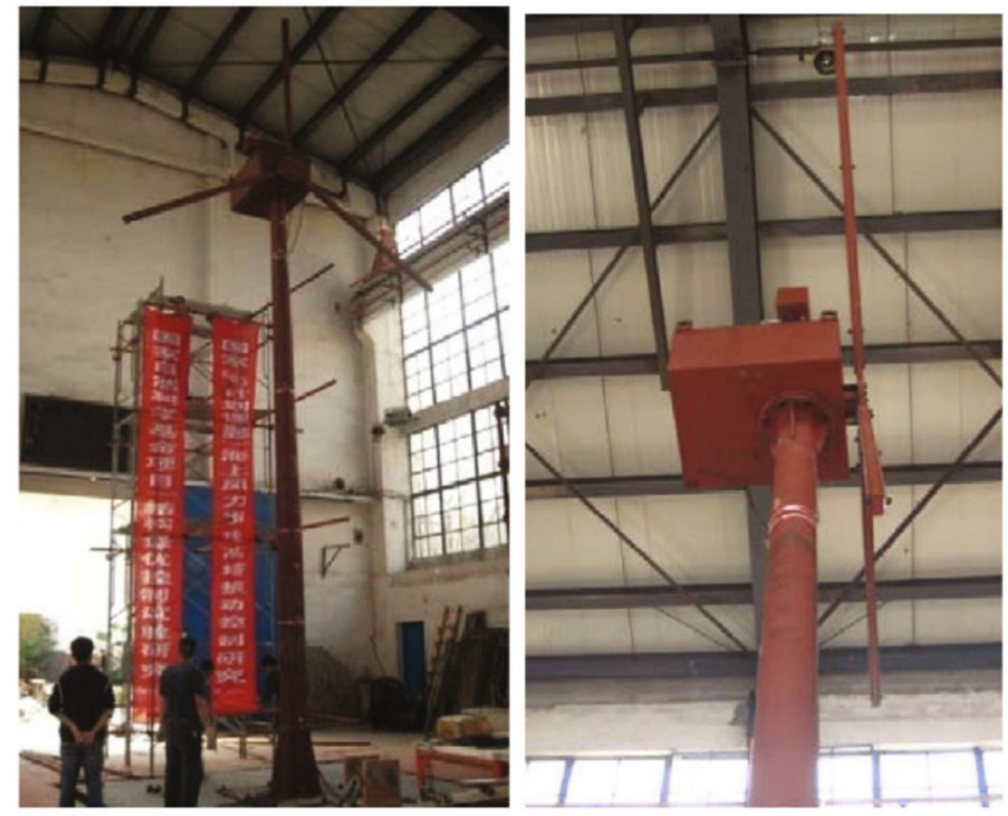

(a)

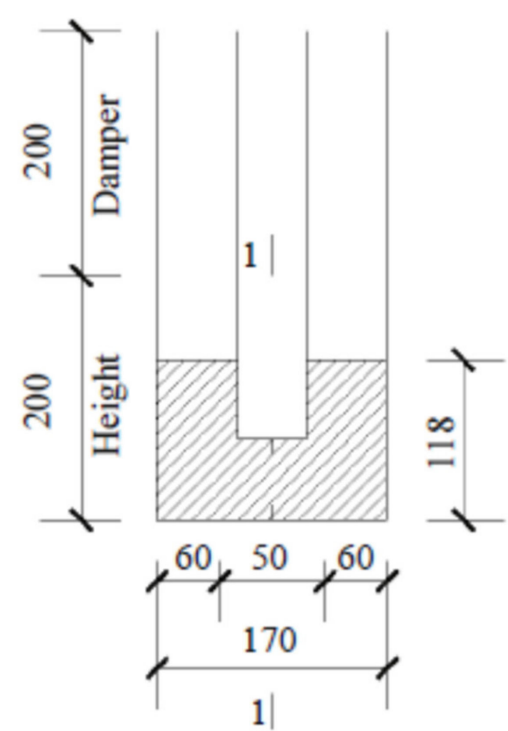

(b)

Figure 26. (a) Experimental setup of offshore WT with TLCD. (b) Dimensions of the proposed TLCD [139].

In addition, it is worth mentioning that TLCDs do not act immediately but rather need a few seconds to be activated when earthquake-induced vibrations are considered [140]. Nevertheless, Hemmati et al., have shown significant improvement in the fragility curves of TLCD-controlled monopile WTs, noting better performance for low-level excitations (where the response is better confined in the linear regime). Their models predicted a maximum fragility reduction of $13 \%$, mentioning, however, that the benefits were almost double for parked compared to operational conditions (Figure 27). This was mostly attributed to aerodynamic damping during operation, demonstrating the disadvantages of a passive linearized absorber for systems with volatile dynamic properties.

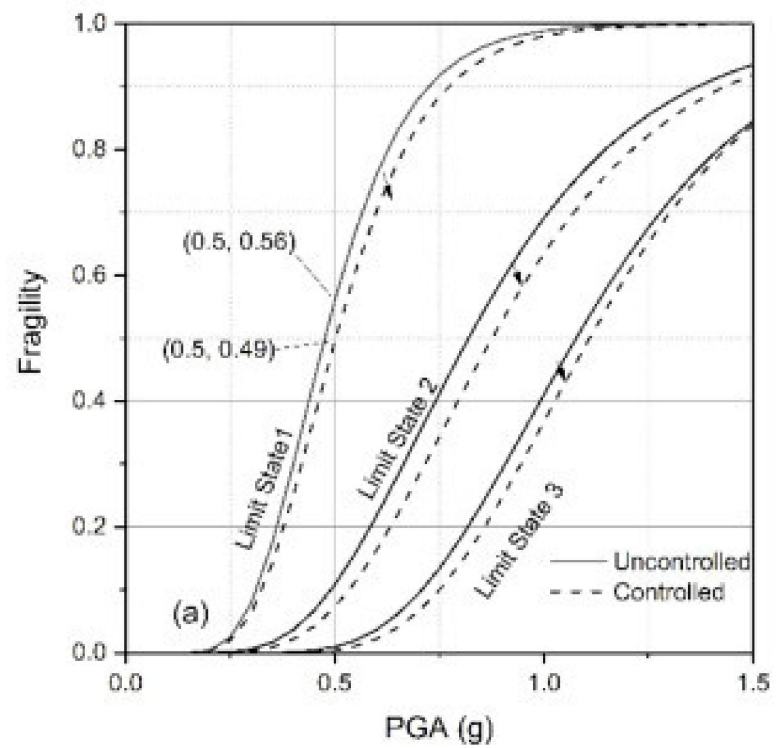

(a)

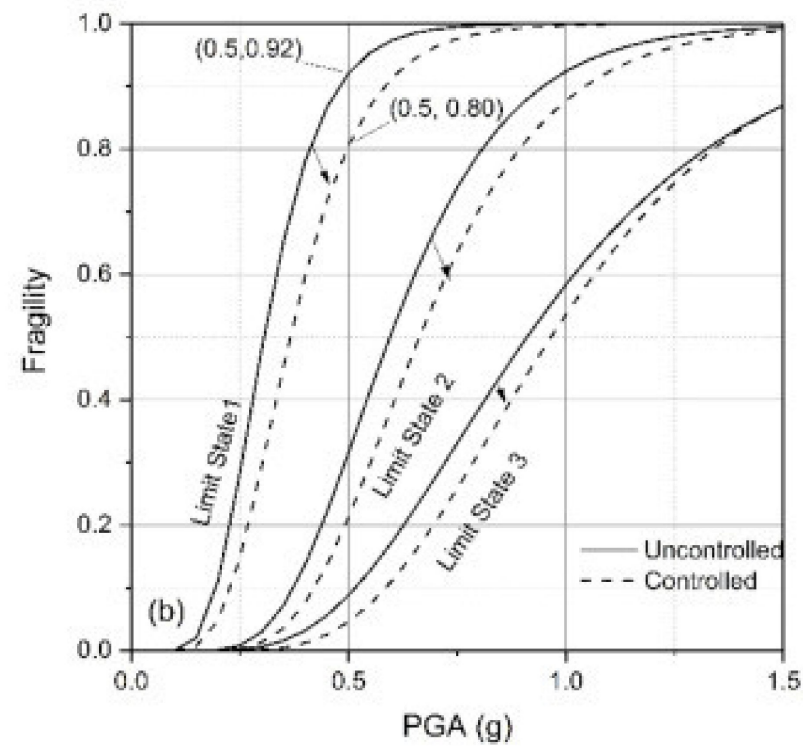

(b)

Figure 27. Fragility curves for uncontrolled and controlled WT considering (a) operational and (b) parked conditions [140]. 
Furthermore, a detuned TLCD can reliably work, but its performance will be negatively affected even by small amounts of detuning [99]. For floating offshore wind turbines, the coupling effect to the rigid body roll motion of the spar is significant, so the TLCD should be controlled according to the shifted tower side-side frequency [141]. Furthermore, the fundamental architecture of TLCDs allows for easier resolution of the directionality issue. Coudurier et al. investigated different configurations of liquid multi-column dampers for a floating wind turbine tower, motivated by the poor TLCD performance under misalignment of the damper (and platform) with the incident waves. In fact, they had shown that misaligned waves lead to complete deactivation of the damper, similarly to the TMD directionality issue for the side-side and fore-aft vibrations of the tower [142]. Different geometries for containers with multiple columns were proposed and compared, such as the 2U damping system, a star-shaped, and a triangular TLCD (Figure 28), with the $2 \mathrm{U}$-shaped one notably occupying $35 \%$ less space than its counterparts. The authors considered the NREL 5-MW baseline wind turbine, with the reported simulation indicating that all designs had similar performance for the platform roll displacement (up to $45^{\circ}$ misalignment), whereas the other two were more effective in mitigating wave-induced pitch displacement [143].

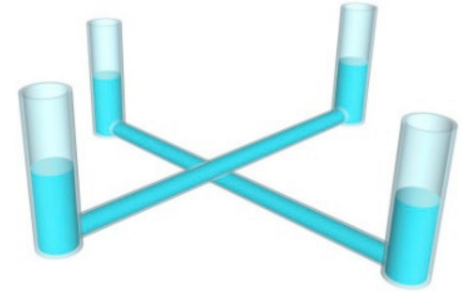

(a)

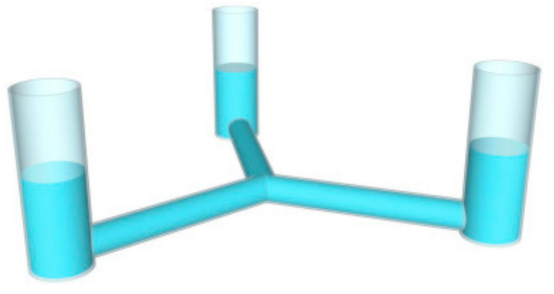

(b)

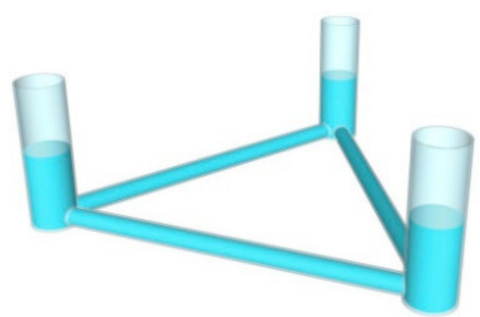

(c)

Figure 28. (a) 2U-shaped TLCD; (b) star-shaped; (c) triangular [143].

Installation space still remains an issue for TLCDs; however, novel contributions such as using an S-shape damper in tension-leg platforms (Figure 29) rather than the conventional U-shape has shown improved performance with less occupied space [144]. Interestingly, a recent study has introduced multi-purpose TLCDs, which combine strong incentives to mitigate vibrations of offshore floating platforms by recycling the kinetic energy of incident waves [145].

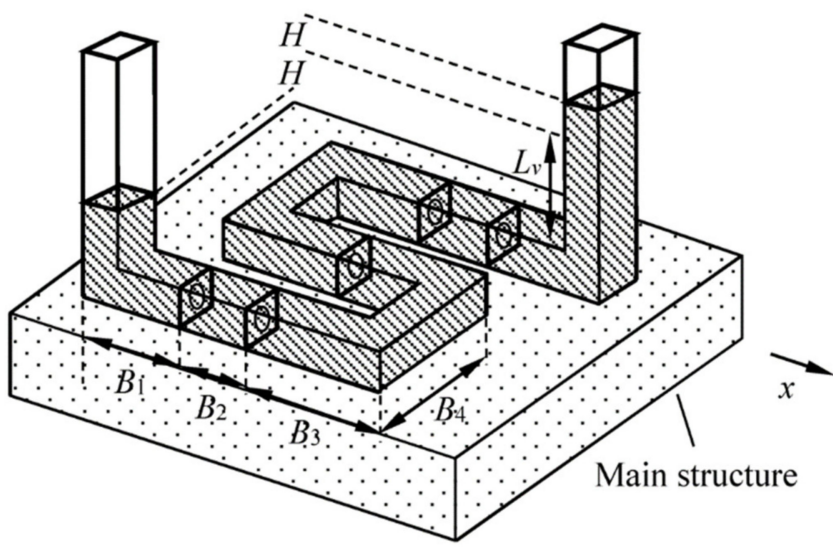

(a)

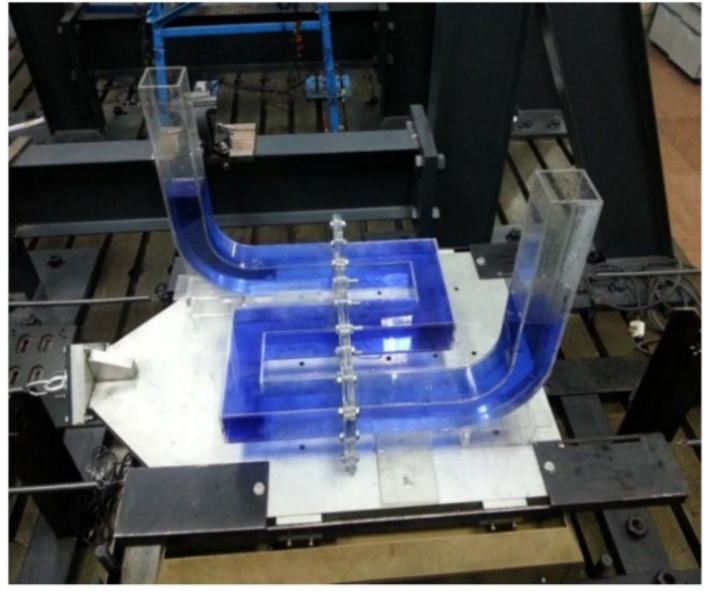

(b)

Figure 29. (a) Sketch of an S-shaped TLCD; (b) prototype for lab testing [144]. 


\subsection{Active Vibration Methods}

The combined action of a damper and a real-time control system creates an active vibration scheme. An Active Tuned Mass Damper (ATMD) is a combination of a TMD and an actuator parallel to the spring and the damper. In general terms, active control methods improve the overall response of the wind turbine tower, significantly decreasing the displacements at the top [146]. Likewise, Fitzgerald et al. concluded that AMTDs increase the reliability of wind turbine towers after performing a fragility analysis [147]. Brodersen et al., compared the structural response of a wind turbine tower with an ATMD and a TMD, demonstrating that the ATMD provided better performance without increasing the damper mass. However, the reduced mass ratio of the damper leads to greater displacements especially for frequencies below the tower frequency, in which TMDs are more efficient [148]. Hu et al., considered an adaptive sliding mode control law to include system uncertainties and external disturbances for a wind turbine with active TMD. The proposed law control showed promising results in comparison with passive TMDs [149]. Salvi et al. compared two other control strategies, one based on the kinematics of the structure and another one based on the acceleration of the structure. Both strategies were found to be efficient with the acceleration-based one presenting better performance [150]. Similarly, using stroke constraints, the active TMDs were found to be more efficient than passive TMDs in terms of fore-aft displacements [151]. Finally, Linear Quadratic Regulator (LQR) and discrete decentralized constrained $\mathrm{H} \infty$ algorithms were used as control methods, reducing the nacelle displacement by $47.9 \%$ and $55.6 \%$, respectively [152]. Compared with passive vibration controllers, active controllers require external power for their function, whereas their performance is subject to the actuator response time, particularly under random load variations. This partly explains why their application is not attractive in the industry. Besides, complicated control algorithms need to be developed, increasing the complexity of the implementation of the method.

\subsection{Semi-Active Vibration Methods}

A semi-active approach combines both passive and active vibration design features. It offers the benefits of active controllers since they can monitor the response of the structure and the dynamic loads, and they require less energy to operate. The main feature of semi-active dampers is the control of the damper properties rather than the application of a large-magnitude active control force. Furthermore, this design feature is able to overcome some of the disadvantages of passive TMDs. Generally, passive TMDs face two main challenges, the detuning effect as well as the limitation of the stroke [113]. Semi-active control provides an opportunity for real-time tuning of the TMD to tackle detuning. Sun studied the effectiveness of semi-active TMDs against multiple hazards, considering the soil-structure interaction for offshore monopile wind turbines. Generally, they observed that both passive and semi-active design concepts mitigated the responses, with the semiactive method being more efficient (Figure 30). Moreover, since the interaction between the structure and the soil may be significant, detuning of the passive damper may result in ineffective response control and a greater stroke. On the contrary, these effects are limited due to the semi-active control of the damper, leading to better behavior against fatigue loads [153].

A novel design feature was proposed by S. Sarkar and A. Chakraborty substituting water in the column damper with magneto-rheological (MR) fluid to simultaneously control the fore-aft and side-side response (Figure 31a,b). Since water is lighter, it requires greater space, calling the efficiency of the TLCD into question. MR fluid is a denser fluid and is characterized as a smart material whose properties can be easily modified through an externally applied magnetic field. The reported results shown in Figure 31c,d show the significant reduction of the response amplitude, particularly for the side-side response, which was reduced by $35.16 \%$ and $35.32 \%$ for $0^{\circ}$ and $4^{\circ}$ pitch angles, respectively [134]. Nevertheless, the authors also showed that the control performance is highly sensitive to the damper's time lag. 
(a)

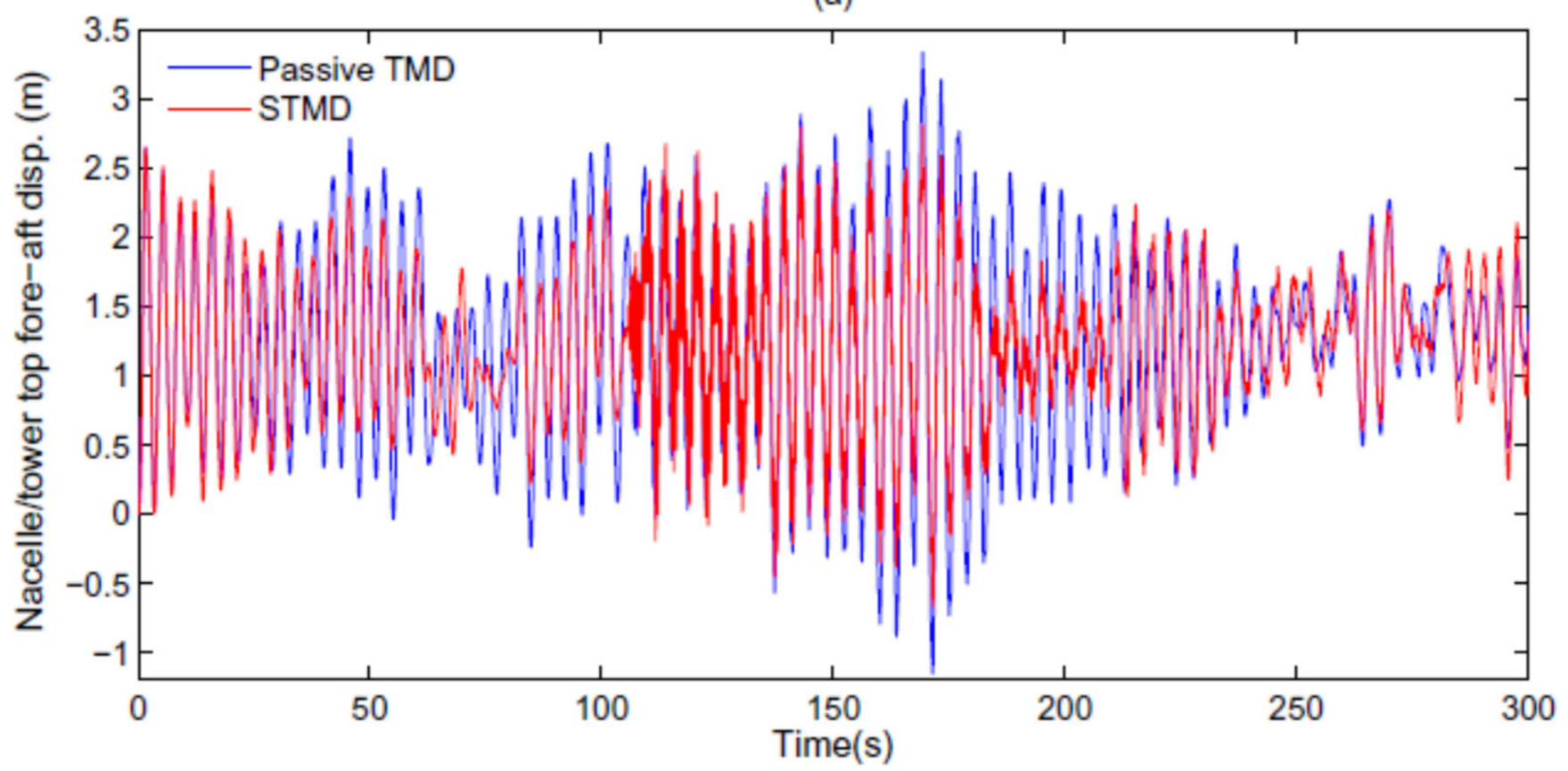

(b)

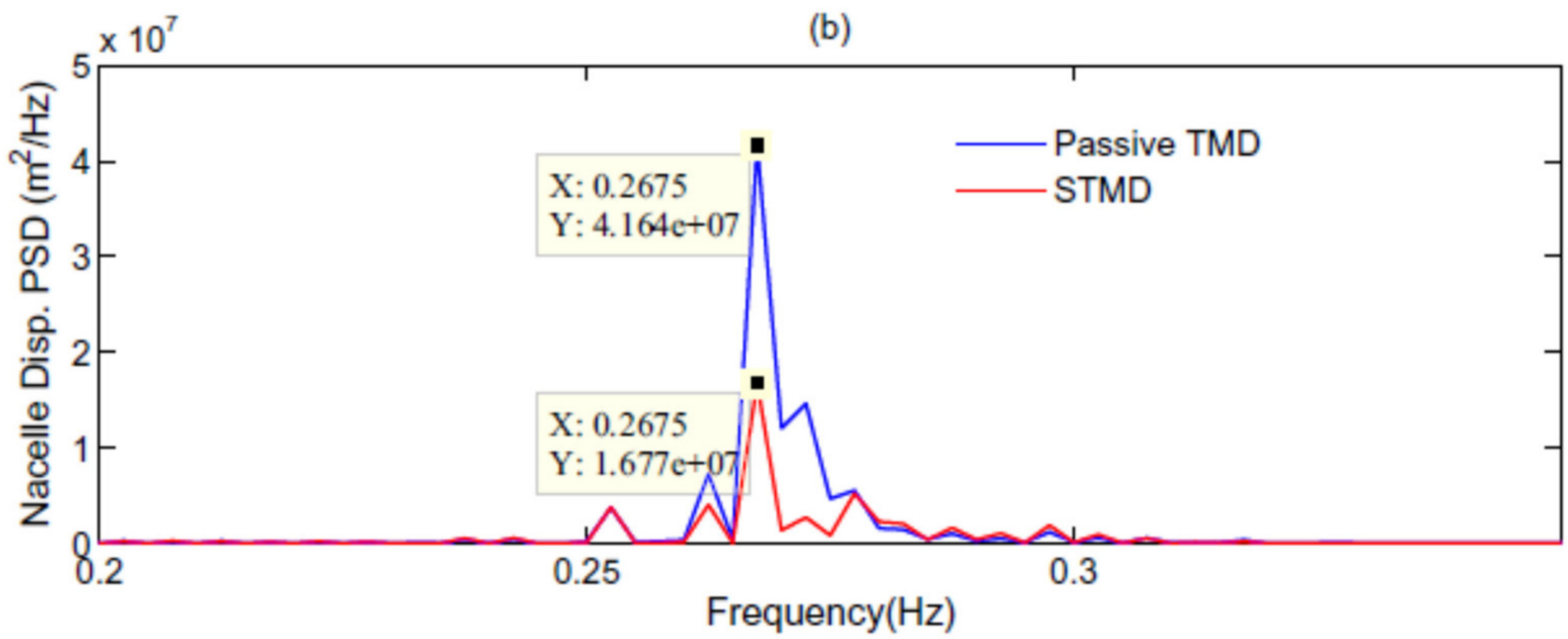

Figure 30. Top displacement mitigation comparison between passive and semi-active TMDs. (a) Time history. (b) Response spectrum [153].

Semi-active MR dampers also improved the response of the undamped side-to-side motion due to misaligned wind and waves [154]. Caterino carried out an experimental analysis studying the performance of the MR damper. The dampers were controlled by a suitable algorithm that monitored the stiffness of the structure in real time. This configuration resulted in reduced bending moments at the base of the structure induced by wind loading [155]. Additionally, in this novel base, the influence of P-Delta effects was investigated. When the control algorithm was perfectly calibrated, the P-Delta effects were negligible [156]. Furthermore, external MR dampers were investigated and found to reduce the vibration due to earthquake loads as well as the duration of the strong ground motion [157]. Martynowicz indicated that using an MR tuned damper in the nacelle reduces the risk of damage due to external vibrations such as wind, waves, and earthquakes, which may lead to a lighter structure and thus decrease the cost of energy [158]. 


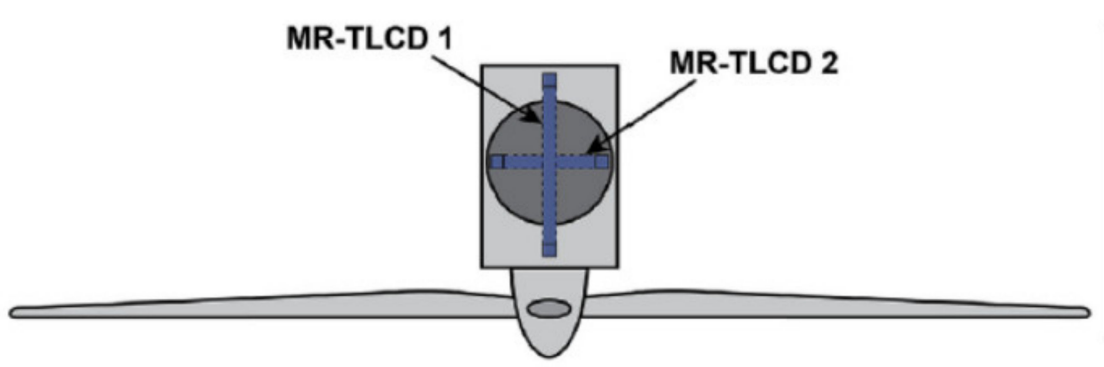

(a)

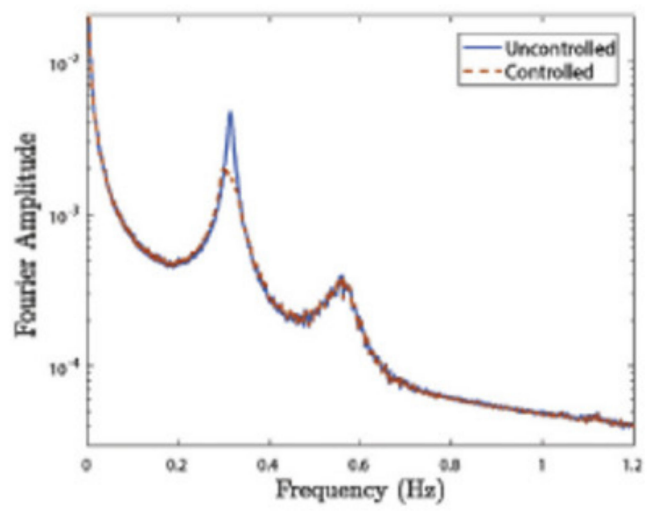

(c)

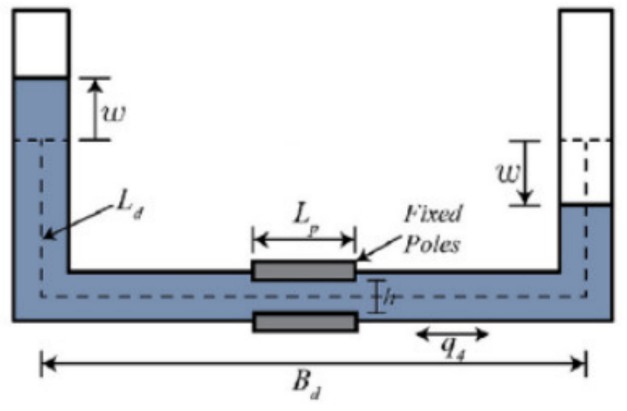

(b)

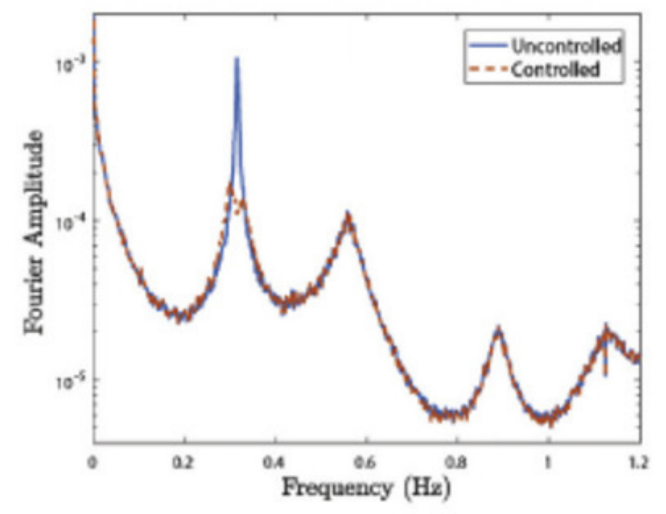

(d)

Figure 31. Bi-directional TLCD with MR-controlled orifice [134]. (a) MR-TLCD location in the nacelle; (b) schematic of a single damper; (c) controlled fore-aft response spectrum compared with uncontrolled under wind load of $10 \mathrm{~m} / \mathrm{s}$; (d) corresponding side-side response.

\section{Conclusions}

Structural control of the vibrations experienced by wind turbine towers is a promising way to prolong the lifecycle of wind energy installations and to increase the survivability of the structure, with a direct positive impact on the energy's LCOE. Giant wind turbines of up to $250 \mathrm{~m}$ are expected to become the next step in the exploitation of wind energy to reduce the energy use impact on climate change. Economic efficiency and reliability of the energy supply necessitate lighter structures with prolonged lifetime, minimized parked durations, reduced maintenance costs and downtime, and mitigation of the risk of collapse. Previous studies have established the benefits of controlling the vibrations of the tower towards the above incentives. Minimized vibration amplitudes reduce the stresses in the structure's sections and the loads transferred to the base, leading to slower fatigue degradation, preventing the excursion of catastrophic failures such as local buckling or bolt looseness, and therefore reducing the risk of collapse.

Passive control methods have been studied extensively to control tower vibrations. Among these, the proven concept of tuned mass dampers has been among the moststudied systems, followed by tuned liquid dampers and tuned liquid column dampers. The latter have provided an elegant solution to the issue of the installation space that TMDs and TLDs typically require and provide easier and more reliable tunability. Significant mitigation of the fundamental structural resonances has been reported, particularly for the side-side direction where aerodynamic damping is relatively low, whereas designs of bidirectional dampers have been proposed to overcome the original constraint of classically tuned mass dampers in one spatial direction. Active control methods have been shown 
to increase the mitigation performance; yet this is achieved at the expense of external power sources, complicated hardware and control requirements, and potentially increased maintenance. Semi-active methods, typically based on smart materials for controllable damping, severely reduce the power requirements offering improved performance once compared with passive methods.

Nevertheless, wind turbine towers are subject to highly random loads from a variety of natural resources, including wind, waves, currents, and earthquakes. Rare extreme conditions are highly unpredictable in the design stage, posing the risk of catastrophic deterioration of the structure. State-of-the-art control dampers have emerged from theoretical analysis under harmonic loading, which has left a gap in the management of single and-even worse-co-incident extreme events that are typically dictated by relatively broadband stochastic spectra. Active methods could possibly provide a solution to this issue; however, the power supply requirements make this approach rather unattractive, whereas the controller response time lag is a critical issue to resolve. Nevertheless, semiactive methods could offer a compromise with considerably less energy demand, fewer fragile support systems, and simpler operation. These systems point to a promising way forward; nevertheless, their operation and performance under multiple stochastic loads should be further explored.

Author Contributions: Conceptualization: G.M, P.A. and C.B., Methodology: G.M., P.A. and C.B., Software: G.M., Validation: G.M., P.A. and C.B., Formal Analysis: G.M. and P.A., Investigation: G.M., Resources: C.B., Data curation: G.M., Writing-Original Draft Presentation: G.M., WritingReview and Editing: P.A. and C.B., Visualization: G.M and P.A., Supervision: P.A. and C.B., Project Administration: P.A. and C.B. All authors have read and agreed to the published version of the manuscript.

Funding: This research received no external funding.

Acknowledgments: The authors would like to acknowledge the contribution of the COST Action CA20109-MODULAR ENERGY ISLANDS FOR SUSTAINABILITY AND RESILIENCE for the fruitful discussions and the support to their research activities.

Conflicts of Interest: There is no conflict of interest.

\section{References}

1. Energy Trends January to March 2021; UK Department for Business Energy and Industrial Strategy: London, UK, 2021.

2. Paris Agreement to the United Nations Framework Convention on Climate Change, 12 December 2015, T.I.A.S. No. 16-1104. Available online: https:/ / eur-lex.europa.eu/content/paris-agreement/paris-agreement.html (accessed on 9 October 2021).

3. European Commission. Communication from the Commission to the European Parliament, the Council, the European Economic and Social Committee and Committee of the Regions: A Policy Framework for Climate and Energy in the Period from 2020 to 2030; European Commission: Brussels, Belgium, 2014.

4. WindEurope. Wind Energy and Economic Recovery in Europe: How Wind Energy Will Put Communities at the Heart of the Green Recovery; WindEurope: Brussels, Belgium, 2020.

5. EU Directive (EU) 2018/2001 of the European Parliament and of the Council of 11 December 2018 on the promotion of the use of energy from renewable sources. Off. J. Eur. Union 2018, 2001, 82-209.

6. WindEurope. Wind Energy in Europe, 2020 Statistics and the Outlook for 2021-2025; WindEurope: Brussels, Belgium, 2021.

7. Malliotakis, G.E.; Nikolaidis, T.N.; Baniotopoulos, C.C. Small wind turbines: Sustainability criteria related to the local built environment. IOP Conf. Ser. Earth Environ. Sci. 2020, 410, 012046. [CrossRef]

8. Veljkovic, M.; Feldmann, M.; Naumes, J.; Pak, D.; Simões da Silva, L.; Rebelo, C. Wind turbine tower design, erection and maintenance. Wind Energy Syst. Optimising Des. Constr. Safe. Reliab. Oper. 2010, 274-300. [CrossRef]

9. Al-falahi, M.D.A.; Jayasinghe, S.D.G.; Enshaei, H. A review on recent size optimization methodologies for standalone solar and wind hybrid renewable energy system. Energy Convers. Manag. 2017, 143, 252-274. [CrossRef]

10. Devine-Wright, P. Beyond NIMBYism: Towards an integrated framework for understanding public perceptions of wind energy. Wind Energy 2005, 8, 125-139. [CrossRef]

11. Graham, J.B.; Stephenson, J.R.; Smith, I.J. Public perceptions of wind energy developments: Case studies from New Zealand. Energy Policy 2009, 37, 3348-3357. [CrossRef]

12. Hu, Y.; Yang, J.; Baniotopoulos, C. Repowering Steel Tubular Wind Turbine Towers Enhancing them by Internal Stiffening Rings. Energies 2020, 13, 1538. [CrossRef] 
13. Zountouridou, E.I.; Kiokes, G.C.; Chakalis, S.; Georgilakis, P.S.; Hatziargyriou, N.D. Offshore floating wind parks in the deep waters of Mediterranean Sea. Renew. Sustain. Energy Rev. 2021, 51, 433-448. [CrossRef]

14. HM Government. ENERGY WHITE PAPER-Powering our Net Zero Future; Queen's Printer and Controller of HMSO 2020; HM Government: London, UK, 2020.

15. Musial, W.; Ram, B. Large-Scale Offshore Wind Power in the United States. Assessment of Opportunities and Barriers; NREL/TP-50040745; National Renewable Energy Lab. (NREL): Golden, CO, USA, 2010; pp. 10-12.

16. Hernandez-Estrada, E.; Lastres-Danguillecourt, O.; Robles-Ocampo, J.B.; Lopez-Lopez, A.; Sevilla-Camacho, P.Y.; PerezSariñana, B.Y.; Dorrego-Portela, J.R. Considerations for the structural analysis and design of wind turbine towers: A review. Renew. Sustain. Energy Rev. 2021, 137, 1-17. [CrossRef]

17. Stavridou, N.; Koltsakis, E.; Baniotopoulos, C.C. Lattice and Tubular Steel Wind Turbine Towers. Comparative Structural Investigation. Energies 2020, 13, 6325. [CrossRef]

18. Kong, C.; Lim, S.; Park, H. A Study on Optimal Design of Filament Winding Composite Tower for 2 MW Class Horizontal Axis Wind Turbine Systems. Proc. ASME Turbo. Expo. 2013, 8, 15-23. [CrossRef]

19. Baniotopoulos, C.C.; Lavassas, I.; Nikolaidis, G.; Zervas, P. Topics on the Design of Tubular Steel Wind Turbine Towers. In Environmental Wind Engineering and Design of Wind Energy Structures. CISM Courses and Lectures; Baniotopoulos, C.C., Borri, C., Stathopoulos, T., Eds.; Springer: Vienna, Austria, 2011; Volume 531, ISBN 978-3-7091-0952-6.

20. Lavassas, I.; Nikolaidis, G.; Zervas, P.; Efthimiou, E.; Doudoumis, I.N.; Baniotopoulos, C.C. Analysis and design of the prototype of a steel 1-MW wind turbine tower. Eng. Struct. 2003, 25, 1097-1106. [CrossRef]

21. Bazeos, N.; Hatzigeorgiou, G.D.; Hondros, I.D.; Karamaneas, H.; Karabalis, D.L.; Beskos, D.E. Static, seismic and stability analyses of a prototype wind turbine steel tower. Eng. Struct. 2002, 24, 1015-1025. [CrossRef]

22. Dimopoulos, C.A.; Gantes, C.J. Experimental investigation of buckling of wind turbine tower cylindrical shells with opening and stiffening under bending. Thin-Walled Struct. 2012, 54, 140-155. [CrossRef]

23. Dimopoulos, C.A.; Gantes, C.J. Comparison of stiffening types of the cutout in tubular wind turbine towers. J. Constr. Steel Res. 2013, 83, 62-74. [CrossRef]

24. Santos, R.R.; Cho, S.J.; Park, J.S. Ultimate Strength of 10 MW Wind Turbine Tower Considering Opening, Stiffener, and Initial Imperfection. Int. J. Steel Struct. 2018, 18, 1318-1324. [CrossRef]

25. Yadav, K.K.; Gerasimidis, S. Imperfection insensitive thin cylindrical shells for next generation wind turbine towers. J. Constr. Steel Res. 2020, 172, 106228. [CrossRef]

26. Muskulus, M. The full-height lattice tower concept. Energy Procedia 2012, 24, 371-377. [CrossRef]

27. Stavridou, N.; Koltsakis, E.; Baniotopoulos, C.C. A comparative life-cycle analysis of tall onshore steel wind-turbine towers. Clean Energy 2020, 4, 48-57. [CrossRef]

28. Sabau, G.; Koltsakis, E.; Lagerqvist, O. Stability analysis of newly developed polygonal cross-sections for lattice wind towers. Wind Eng. 2018, 42, 353-363. [CrossRef]

29. Von Der Haar, C.; Marx, S. Design aspects of concrete towers for wind turbines. J. South. African Inst. Civ. Eng. 2015, 57, 30-37. [CrossRef]

30. De Lana, J.A.; Júnior, P.A.A.M.; Magalhães, C.A.; Magalhães, A.L.M.A.; de Andrade Junior, A.C.; de Barros Ribeiro, M.S. Behavior study of prestressed concrete wind-turbine tower in circular cross-section. Eng. Struct. 2021, 227, 111403. [CrossRef]

31. Quilligan, A.; O'Connor, A.; Pakrashi, V. Fragility analysis of steel and concrete wind turbine towers. Eng. Struct. 2012, 36, 270-282. [CrossRef]

32. Ma, H.; Meng, R. Optimization design of prestressed concrete wind-turbine tower. Sci. China Technol. Sci. 2014, 57, 414-422. [CrossRef]

33. Jin, Q.; Li, V.C. Development of lightweight engineered cementitious composite for durability enhancement of tall concrete wind towers. Cem. Concr. Compos. 2018, 96, 87-94. [CrossRef]

34. Young, A.C.; Goupee, A.J.; Dagher, H.J.; Viselli, A.M. Methodology for optimizing composite towers for use on floating wind turbines. J. Renew. Sustain. Energy 2017, 9, 033305. [CrossRef]

35. Schaumann, I.; Keindorf, D. Sandwich-Towers for Wind Energy Converters. Dewi Mag. 2008, 460, 65-76.

36. Vernardos, S.M.; Gantes, C.J. Cross-section optimization of sandwich-type cylindrical wind turbine towers. Am. J. Eng. Appl. Sci. 2015, 8, 471-480. [CrossRef]

37. Van Der Zee, T.; De Ruiter, M.J.; Wieling, I. The C-Tower project-A composite tower for offshore wind turbines. Energy Proc. 2017, 137, 401-405. [CrossRef]

38. Polyzois, D.J.; Raftoyiannis, I.G.; Ungkurapinan, N. Static and dynamic characteristics of multi-cell jointed GFRP wind turbine towers. Compos. Struct. 2009, 90, 34-42. [CrossRef]

39. Mohammadi, M.R.S.; Farhan, M.; Rebelo, C.; Veljković, M. Preliminary transition piece design for an onshore wind turbine. In Proceedings of the EUROSTEEL 2017, Copenhagen, Denmark, 13-15 September 2017; Volume 1, pp. 4400-4409.

40. Jovašević, S.; Shah Mohammadi, M.R.; Rebelo, C.; Pavlović, M.; Veljković, M. New Lattice-Tubular Tower for Onshore WEC -Part 1: Structural Optimization. Procedia Eng. 2017, 199, 3236-3241. [CrossRef]

41. Gkantou, M.; Martinez-Vazquez, P.; Baniotopoulos, C. On the structural response of a tall hybrid onshore wind turbine tower. Procedia Eng. 2017, 199, 3200-3205. [CrossRef] 
42. Gkantou, M.; Rebelo, C.; Baniotopoulos, C. Life Cycle assessment of tall onshore hybrid steel wind turbine towers. Energies 2020, 13, 3950. [CrossRef]

43. Alvarez-Anton, L.; Koob, M.; Diaz, J.; Minnert, J. Optimization of a hybrid tower for onshore wind turbines by Building Information Modeling and prefabrication techniques. Vis. Eng. 2016, 4, 1-9. [CrossRef]

44. Ozdemir, A.; Sermet, F.; Ensari Yigit, M.; Arisoy, B.; Ercan, E. Static analysis of different type of wind turbine towers. In Proceedings of the International Conference on Wind Energy Harvesting, Coimbra, Portugal, 20-21 April 2017.

45. Rebelo, C.; Moura, A.; Gervásio, H.; Veljkovic, M.; Simões da Silva, L. Comparative life cycle assessment of tubular wind towers and foundations - Part 1: Structural design. Eng. Struct. 2014, 74, 283-291. [CrossRef]

46. Matos, R.P.; Pinto, P.L.; Rebelo, C.S.; Gervásio, H.S.; Veljkovic, M. Improved design of tubular wind tower foundations using steel micropiles. Struct. Infrastruct. Eng. 2016, 12, 1038-1050. [CrossRef]

47. Martínez, E.; Sanz, F.; Pellegrini, S.; Jiménez, E.; Blanco, J. Life-cycle assessment of a 2-MW rated power wind turbine: CML method. Int. J. Life Cycle Assess. 2009, 14, 52-63. [CrossRef]

48. Lavanya, C.; Kumar, N.D. Foundation Types for Land and Offshore Sustainable Wind Energy Turbine Towers. E3S Web Conf. 2020, 184, 1-6. [CrossRef]

49. Michel, P.; Butenweg, C.; Klinkel, S. Pile-grid foundations of onshore wind turbines considering soil-structure-interaction under seismic loading. Soil Dyn. Earthq. Eng. 2018, 109, 299-311. [CrossRef]

50. Veljkovic, M.; Heistermann, C.; Husson, W.; Limam, M.; Feldmann, M.; Naumes, J.; Pak, D.; Fabe, T.; Klose, M.; Fruhner, K.-U.; et al. High Steel Tubular Towers for Wind Turbines (HISTWIN2); Final Report-RFSR-CT-2010-00031; Publications Office of the European Union: Brussels, Belgium, 2012.

51. Wang, X.; Zeng, X.; Li, J.; Yang, X.; Wang, H. A review on recent advancements of substructures for offshore wind turbines. Energy Convers. Manag. 2018, 158, 103-119. [CrossRef]

52. Koh, J.H.; Ng, E.Y.K. Downwind offshore wind turbines: Opportunities, trends and technical challenges. Renew. Sustain. Energy Rev. 2016, 54, 797-808. [CrossRef]

53. Vaiana, N.; Sessa, S.; Marmo, F.; Rosati, L. A class of uniaxial phenomenological models for simulating hysteretic phenomena in rate-independent mechanical systems and materials. Nonlinear Dyn. 2018, 93, 1647-1669. [CrossRef]

54. Vaiana, N.; Sessa, S.; Rosati, L. A generalized class of uniaxial rate-independent models for simulating asymmetric mechanical hysteresis phenomena. Mech. Syst. Signal. Process. 2021, 146, 106984. [CrossRef]

55. Chen, W.; Guo, S.; Li, Y.; Shen, Y. Impacts of mooring-lines hysteresis on dynamic response of spar floating wind turbine. Energies 2021, 14, 2109. [CrossRef]

56. Damiani, R.R. 10-Design of offshore wind turbine towers. In Offshore Wind Farms; Ng, C., Li, R., Eds.; Woodhead Publishing: Duxford, UK; Elsevier Ltd.: Amsterdam, The Netherlands, 2016; ISBN 9780081007808.

57. Lochan, S.; Mehmanparast, A.; Wintle, J. A review of fatigue performance of bolted connections in offshore wind turbines. Procedia Struct. Integr. 2019, 17, 276-283. [CrossRef]

58. Mehmanparast, A.; Lotfian, S.; Vipin, S.P. A review of challenges and opportunities associated with bolted flange connections in the offshore wind industry. Metals 2020, 10, 732. [CrossRef]

59. Schaumann, P.; Eichstädt, R. Experimental and Analytical Fatigue Assessment of High-Strength Bolts for Wind Turbine Structures. In Proceedings of the Conference: Kolloquium zum 60. Geburtstag von Herrn Prof. Dr.-Ing. Jörg Lange At: TU Darmstadt, Institut für Stahlbau und Werkstoffmechanik, Darmstand, Germany, 8 July 2018.

60. Braithwaite, J.; Mehmanparast, A. Analysis of tightening sequence effects on preload behaviour of offshore wind turbine M72 bolted connections. Energies 2019, 12, 4406. [CrossRef]

61. Madsen, C.A.; Kragh-Poulsen, J.C.; Thage, K.J.; Andreassen, M.J. Analytical and numerical investigation of bolted steel ring flange connection for offshore wind monopile foundations. IOP Conf. Ser. Mater. Sci. Eng. 2017, 276, 012024. [CrossRef]

62. Stavridou, N.; Efthymiou, E.; Baniotopoulos, C.C. Welded connections of wind turbine towers under fatigue loading: Finite element analysis and comparative study. Am. J. Eng. Appl. Sci. 2015, 8, 489-503. [CrossRef]

63. Alonso-Martinez, M.; Adam, J.M.; Alvarez-Rabanal, F.P.; del Coz Díaz, J.J. Wind turbine tower collapse due to flange failure: FEM and DOE analyses. Eng. Fail. Anal. 2019, 104, 932-949. [CrossRef]

64. Schaumann, P.; Raba, A.; Bechtel, A. Fatigue behaviour of grouted connections at different ambient conditions and loading scenarios. Energy Procedia 2017, 137, 196-203. [CrossRef]

65. Dallyn, P.; El-Hamalawi, A.; Palmeri, A.; Knight, R. Experimental testing of grouted connections for offshore substructures: A critical review. Structures 2015, 3, 90-108. [CrossRef]

66. Cabboi, A.; Segeren, M.; Hendrikse, H.; Metrikine, A. Vibration-assisted installation and decommissioning of a slip-joint. Eng. Struct. 2020, 209, 1-16. [CrossRef]

67. Iliopoulos, A.N.; Van Hemelrijck, D.; Vlassenbroeck, J.; Aggelis, D.G. Assessment of grouted samples from monopile wind turbine foundations using combined non-destructive techniques. Constr. Build. Mater. 2016, 122, 855-862. [CrossRef]

68. Tziavos, N.I.; Hemida, H.; Metje, N.; Baniotopoulos, C. Non-linear finite element analysis of grouted connections for offshore monopile wind turbines. Ocean. Eng. 2019, 171, 633-645. [CrossRef]

69. DNV Offshore Standard DNV-OS-J101. DNV 2010, 1-142.

70. Lotsberg, I.; Serednicki, A.; Bertnes, H.; Lervik, A. Design of grouted connections for monopile offshore structures: Results from two Joint Industry Projects. Stahlbau 2012, 81, 695-704. [CrossRef] 
71. Gollub, P.; Jensen, J.F.; Giese, D.; Güres, S. Flanged foundation connection of the offshore wind farm Amrumbank West-Concept, approval, design, tests and installation. Stahlbau 2014, 83, 522-528. [CrossRef]

72. Tziavos, N.I.; Hemida, H.; Metje, N.; Baniotopoulos, C. Grouted connections on offshore wind turbines: A review. Proc. Inst. Civ. Eng. Eng. Comput. Mech. 2016, 169, 183-195. [CrossRef]

73. Veljkovic, M.; Heistermann, C.; Husson, W.; Limam, M.; Feldmann, M.; Naumes, J.; Pak, D.; Fabe, T.; Klose, M.; Fruhner, K.-U.; et al. High Strength Tower in Steel for Wind Turbines (HISTWIN); Final Report-RFSR-CT-2006-00031; Publications Office of the European Union: Brussels, Belgium, 2012.

74. Pavlović, M.; Heistermann, C.; Veljković, M.; Pak, D.; Feldmann, M.; Rebelo, C.; Simões da Silva, L. Friction connection vs. ring flange connection in steel towers for wind converters. Eng. Struct. 2015, 98, 151-162. [CrossRef]

75. Pavlović, M.; Heistermann, C.; Veljković, M.; Pak, D.; Feldmann, M.; Rebelo, C.; Da Silva, L.S. Connections in towers for wind converters, part I: Evaluation of down-scaled experiments. J. Constr. Steel Res. 2015, 115, 445-457. [CrossRef]

76. Segeren, M.L.A.; Lourens, E.M.; Tsouvalas, A.; Van Der Zee, T.J.J. Investigation of a slip joint connection between the monopile and the tower of an offshore wind turbine. IET Renew. Power Gener. 2014, 8, 422-432. [CrossRef]

77. Ma, Y.; Martinez-Vazquez, P.; Baniotopoulos, C. Wind turbine tower collapse cases: A historical overview. Proc. Inst. Civ. Eng. Struct. Build. 2019, 172, 547-555. [CrossRef]

78. Zhao, Z.; Dai, K.; Camara, A.; Bitsuamlak, G.; Sheng, C. Wind Turbine Tower Failure Modes under Seismic and Wind Loads. J. Perform. Constr. Facil. 2019, 33, 4019015. [CrossRef]

79. Nuta, E.; Christopoulos, C.; Packer, J.A. Methodology for seismic risk assessment for tubular steel wind turbine towers: Application to canadian seismic environment. Can. J. Civ. Eng. 2011, 38, 293-304. [CrossRef]

80. Zhang, Z.; Li, J.; Zhuge, P. Failure analysis of large-scale wind power structure under simulated typhoon. Math. Probl. Eng. 2014, 2014. [CrossRef]

81. Ishihara, T.; Yamaguchi, A.; Takahara, K.; Mekaru, T.; Matsuura, S. An analysis of damaged wind turbines by typhoon Maemi. In Proceedings of the Sixth Asia Pacific Conference on Wind Engineering (APCWE-VI), Seoul, Korea, 12-14 September 2005.

82. Li, Z.; Chen, S.; Ma, H.; Feng, T. Design defect of wind turbine operating in typhoon activity zone. Eng. Fail. Anal. 2013, 27, 165-172. [CrossRef]

83. Chen, X.; Li, C.; Xu, J. Failure investigation on a coastal wind farm damaged by super typhoon: A forensic engineering study. J. Wind Eng. Ind. Aerodyn. 2015, 147, 132-142. [CrossRef]

84. Chou, J.S.; Ou, Y.C.; Lin, K.Y.; Wang, Z.J. Structural failure simulation of onshore wind turbines impacted by strong winds. Eng. Struct. 2018, 162, 257-269. [CrossRef]

85. European Committee for Standardization. Eurocode 8: Design of Structures for Earthquake Resistance-Part 1: General Rules, Seismic Actions and Rules for Buildings, 1st ed.; CEN: Brussels, Belgium, 2004.

86. Katsanos, E.I.; Thöns, S.; Georgakis, C.T.G. Wind turbines and seismic hazard: A state-of-the-art review. Wind Energy 2016, 19, 2113-2133. [CrossRef]

87. Stamatopoulos, G.N. Response of a wind turbine subjected to near-fault excitation and comparison with the Greek Aseismic Code provisions. Soil Dyn. Earthq. Eng. 2013, 46, 77-84. [CrossRef]

88. Sadowski, A.J.; Camara, A.; Málaga-Chuquitaype, C.; Dai, K. Seismic analysis of a tall metal wind turbine support tower with realistic geometric imperfections. J. Int. Assoc. Earthq. Eng. 2016, 46, 201-219. [CrossRef]

89. Smith, V.; Mahmoud, H. Multihazard Assessment of Wind Turbine Towers under Simultaneous Application of Wind, Operation, and Seismic Loads. J. Perform. Constr. Facil. 2016, 30, 4016043. [CrossRef]

90. Asareh, M.A.; Schonberg, W.; Volz, J. Fragility analysis of a 5-MW NREL wind turbine considering aero-elastic and seismic interaction using finite element method. Finite Elem. Anal. Des. 2016, 120, 57-67. [CrossRef]

91. Patil, A.; Jung, S.; Kwon, O.S. Structural performance of a parked wind turbine tower subjected to strong ground motions. Eng. Struct. 2016, 120, 92-102. [CrossRef]

92. Hu, Y.; Yang, J.; Baniotopoulos, C.; Wang, X.; Deng, X. Dynamic analysis of offshore steel wind turbine towers subjected to wind, wave and current loading during construction. Ocean. Eng. 2020, 216, 108084. [CrossRef]

93. Wei, K.; Arwade, S.R.; Myers, A.T. Incremental wind-wave analysis of the structural capacity of offshore wind turbine support structures under extreme loading. Eng. Struct. 2014, 79, 58-69. [CrossRef]

94. Wang, P.; Zhao, M.; Du, X.; Liu, J.; Xu, C. Wind, wave and earthquake responses of offshore wind turbine on monopile foundation in clay. Soil Dyn. Earthq. Eng. 2018, 113, 47-57. [CrossRef]

95. Zuo, H.; Bi, K.; Hao, H.; Li, C. Influence of earthquake ground motion modelling on the dynamic responses of offshore wind turbines. Soil Dyn. Earthq. Eng. 2019, 121, 151-167. [CrossRef]

96. Kim, D.H.; Lee, S.G.; Lee, I.K. Seismic fragility analysis of 5MW offshore wind turbine. Renew. Energy 2014, 65, 250-256. [CrossRef]

97. Mo, R.; Kang, H.; Li, M.; Zhao, X. Seismic fragility analysis of monopile offshore wind turbines under different operational conditions. Energies 2017, 10, 1037. [CrossRef]

98. Koulatsou, K.G.; Kazakis, G.; Gantes, C.J.; Lagaros, N.D. Resonance Investigation and its Effects on Weight Optimization of Tubular Steel Wind Turbine Towers. Procedia Manuf. 2020, 44, 4-11. [CrossRef]

99. Buckley, T.; Watson, P.; Cahill, P.; Jaksic, V.; Pakrashi, V. Mitigating the structural vibrations of wind turbines using tuned liquid column damper considering soil-structure interaction. Renew. Energy 2018, 120, 322-341. [CrossRef] 
100. Wang, L.; Zhong, R.; Liu, L. Resonance characteristics of onshore wind turbine tower structure considering the impedance of piled foundations. Arab. J. Geosci. 2020, 13, 1-10. [CrossRef]

101. Kühn, M.J. Dynamics and design optimisation of offshore wind energy conversion systems. Ph.D. Thesis, Technical University of Delft, Berlin, Germany, 2001.

102. Ko, Y.Y. A simplified structural model for monopile-supported offshore wind turbines with tapered towers. Renew. Energy 2020, 156, 777-790. [CrossRef]

103. Germanischer Lloyd. Guideline for the Certification of Wind Turbines; Germanischer Lloyd: Hamburg, Germany, 2010.

104. Det Norske Veritas (DNV) and Wind Energy Department, RisøNational Laboratory. Guidelines for Design of Wind Turbines, 2nd ed.; DNV/Risø: Copehangen, Denmark, 2002.

105. LeBlanc, C.; Houlsby, G.T.; Byrne, B.W. Response of stiff piles in sand to long-term cyclic lateral loading. Geotechnique 2010, 60, 79-90. [CrossRef]

106. Van der Tempel, J.; Molenaar, D.P. Wind turbine structural dynamics-A review of the principles for modern power generation, onshore and offshore. Wind Eng. 2002, 26, 211-220. [CrossRef]

107. Corciulo, S.; Zanoli, O.; Pisanò, F. Transient response of offshore wind turbines on monopiles in sand: Role of cyclic hydromechanical soil behaviour. Comput. Geotech. 2017, 83, 221-238. [CrossRef]

108. Zaaijer, M.B. Foundation modelling to assess dynamic behaviour of offshore wind turbines. Appl. Ocean. Res. 2006, 28 , 45-57. [CrossRef]

109. Jung, S.; Kim, S.R.; Patil, A.; Hung, L.C. Effect of monopile foundation modeling on the structural response of a 5-MW offshore wind turbine tower. Ocean. Eng. 2015, 109, 479-488. [CrossRef]

110. Klein, M.; Butenweg, C.; Klinkel, S. The Influence of Soil-Structure-Interaction on the Fatigue Analysis in the Foundation Design of Onshore Wind Turbines. Procedia Eng. 2017, 199, 3218-3223. [CrossRef]

111. Ali, A.; De Risi, R.; Sextos, A. Seismic assessment of wind turbines: How crucial is rotor-nacelle-assembly numerical modeling? Soil Dyn. Earthq. Eng. 2021, 141, 106483. [CrossRef]

112. Prendergast, L.J.; Gavin, K.; Doherty, P. An investigation into the effect of scour on the natural frequency of an offshore wind turbine. Ocean. Eng. 2015, 101, 1-11. [CrossRef]

113. Xie, F.; Aly, A. Structural control and vibration issues in wind turbines: A review. Eng. Struct. 2020, 210, 110087. [CrossRef]

114. Murtagh, P.J.; Ghosh, A.; Basu, B.; Broderick, B.M. Passive control of wind turbine vibrations including blade/tower interaction and rotationally sampled turbulence. Wind Energy 2008, 11, 305-317. [CrossRef]

115. Tong, X.; Zhao, X.; Zhao, S. Passive structural vibration control of a monopile wind turbine tower. In Proceedings of the 2015 54th IEEE Conference on Decision and Control (CDC), Osaka, Japan, 15-18 December 2015; pp. 1352-1357. [CrossRef]

116. Zuo, H.; Bi, K.; Hao, H. A state-of-the-art review on the vibration mitigation of wind turbines. Renew. Sustain. Energy Rev. 2020, 121, 109710. [CrossRef]

117. Si, Y.; Karimi, H.R.; Gao, H. Modelling and optimization of a passive structural control design for a spar-type floating wind turbine. Eng. Struct. 2014, 69, 168-182. [CrossRef]

118. Stewart, G.; Lackner, M. Offshore wind turbine load reduction employing optimal passive tuned mass damping systems. IEEE Trans. Control. Syst. Technol. 2013, 21, 1090-1104. [CrossRef]

119. Jahangiri, V.; Sun, C. Three-dimensional vibration control of offshore floating wind turbines using multiple tuned mass dampers. Ocean. Eng. 2020, 206, 107196. [CrossRef]

120. Sun, C.; Jahangiri, V. Bi-directional vibration control of offshore wind turbines using a 3D pendulum tuned mass damper. Mech. Syst. Signal. Process. 2018, 105, 338-360. [CrossRef]

121. Hussan, M.; Rahman, M.S.; Sharmin, F.; Kim, D.; Do, J. Multiple tuned mass damper for multi-mode vibration reduction of offshore wind turbine under seismic excitation. Ocean. Eng. 2018, 160, 449-460. [CrossRef]

122. Gaur, S.; Elias, S.; Höbbel, T.; Matsagar, V.A.; Thiele, K. Tuned mass dampers in wind response control of wind turbine with soil-structure interaction. Soil Dyn. Earthq. Eng. 2020, 132, 106071. [CrossRef]

123. Dai, K.; Huang, H.; Lu, Y.; Meng, J.; Mao, Z.; Camara, A. Effects of soil-structure interaction on the design of tuned mass damper to control the seismic response of wind turbine towers with gravity base. Wind Energy 2021, 24, 323-344. [CrossRef]

124. Chen, D.; Huang, S.; Huang, C.; Liu, R.; Ouyang, F. Passive control of jacket-type offshore wind turbine vibrations by single and multiple tuned mass dampers. Mar. Struct. 2021, 77, 1-19. [CrossRef]

125. Leng, D.; Yang, Y.; Xu, K.; Li, Y.; Liu, G.; Tian, X.; Xie, Y. Vibration control of offshore wind turbine under multiple hazards using single variable-stiffness tuned mass damper. Ocean. Eng. 2021, 236, 109473. [CrossRef]

126. Chen, J.; Georgakis, C.T. Tuned rolling-ball dampers for vibration control in wind turbines. J. Sound Vib. 2013, 332, 5271-5282. [CrossRef]

127. Lian, J.; Zhao, Y.; Lian, C.; Wang, H.; Dong, X.; Jiang, Q.; Zhou, H.; Jiang, J. Application of an eddy current-tuned mass damper to vibration mitigation of offshore wind turbines. Energies 2018, 11, 3319. [CrossRef]

128. Ghaemmaghami, A.; Kianoush, R.; Yuan, X.X. Numerical Modeling of Dynamic Behavior of Annular Tuned Liquid Dampers for Applications in Wind Towers. Comput. Civ. Infrastruct. Eng. 2013, 28, 38-51. [CrossRef]

129. Ha, M.; Cheong, C. Pitch motion mitigation of spar-type floating substructure for offshore wind turbine using multilayer tuned liquid damper. Ocean. Eng. 2016, 116, 157-164. [CrossRef] 
130. Zhang, Z.; Staino, A.; Basu, B.; Nielsen, S.R.K. Performance evaluation of full-scale tuned liquid dampers (TLDs) for vibration control of large wind turbines using real-time hybrid testing. Eng. Struct. 2016, 126, 417-431. [CrossRef]

131. Zhang, Z.; Basu, B.; Nielsen, S.R.K. Real-time hybrid aeroelastic simulation of wind turbines with various types of full-scale tuned liquid dampers. Wind Energy 2019, 22, 239-256. [CrossRef]

132. Ruiz, R.O.; Lopez-Garcia, D.; Taflanidis, A.A. Modeling and experimental validation of a new type of tuned liquid damper. Acta Mech. 2016, 227, 3275-3294. [CrossRef]

133. Yang, W.; Tian, W.; Hvalbye, O.; Peng, Z.; Wei, K.; Tian, X. Experimental research for stabilizing offshore floating wind turbines. Energies 2019, 12, 1947. [CrossRef]

134. Sarkar, S.; Chakraborty, A. Development of semi-active vibration control strategy for horizontal axis wind turbine tower using multiple magneto-rheological tuned liquid column dampers. J. Sound Vib. 2019, 457, 15-36. [CrossRef]

135. Wu, J.C.; Shih, M.H.; Lin, Y.Y.; Shen, Y.C. Design guidelines for tuned liquid column damper for structures responding to wind. Eng. Struct. 2005, 27, 1893-1905. [CrossRef]

136. Colwell, S.; Basu, B. Tuned liquid column dampers in offshore wind turbines for structural control. Eng. Struct. 2009, 31, 358-368. [CrossRef]

137. Mensah, A.F.; Dueñas-Osorio, L. Improved reliability of wind turbine towers with tuned liquid column dampers (TLCDs). Struct. Saf. 2014, 47, 78-86. [CrossRef]

138. Hemmati, A.; Oterkus, E.; Khorasanchi, M. Vibration suppression of offshore wind turbine foundations using tuned liquid column dampers and tuned mass dampers. Ocean. Eng. 2019, 172, 286-295. [CrossRef]

139. Chen, J.; Liu, Y.; Bai, X. Shaking table test and numerical analysis of offshore wind turbine tower systems controlled by TLCD. Earthq. Eng. Eng. Vib. 2015, 14, 55-75. [CrossRef]

140. Hemmati, A.; Oterkus, E.; Barltrop, N. Fragility reduction of offshore wind turbines using tuned liquid column dampers. Soil Dyn. Earthq. Eng. 2019, 125, 105705. [CrossRef]

141. Zhang, Z.; Høeg, C. Vibration control of floating offshore wind turbines using liquid column dampers. J. Phys. Conf. Ser. 2018, 1037, 032002. [CrossRef]

142. Coudurier, C.; Lepreux, O.; Petit, N. Passive and semi-active control of an offshore floating wind turbine using a tuned liquid column damper. IFAC-PapersOnLine 2015, 28, 241-247. [CrossRef]

143. Coudurier, C.; Lepreux, O.; Petit, N. Modelling of a tuned liquid multi-column damper. Application to floating wind turbine for improved robustness against wave incidence. Ocean. Eng. 2018, 165, 277-292. [CrossRef]

144. Zeng, X.; Yu, Y.; Zhang, L.; Liu, Q.; Wu, H. A new energy-absorbing device for motion suppression in deep-sea floating platforms. Energies 2015, 8, 111-132. [CrossRef]

145. Yu, J.; Li, Z.; Yu, Y.; Hao, S.; Fu, Y.; Cui, Y.; Xu, L.; Wu, H. Design and Performance Assessment of Multi-Use Offshore Tension Leg Platform Equipped with an Embedded Wave Energy Converter System. Energies 2020, 13, 3991. [CrossRef]

146. Rahman, M.; Ong, Z.C.; Chong, W.T.; Julai, S.; Khoo, S.Y. Performance enhancement of wind turbine systems with vibration control: A review. Renew. Sustain. Energy Rev. 2015, 51, 43-54. [CrossRef]

147. Fitzgerald, B.; Sarkar, S.; Staino, A. Improved reliability of wind turbine towers with active tuned mass dampers (ATMDs). J. Sound Vib. 2018, 419, 103-122. [CrossRef]

148. Brodersen, M.L.; Bjørke, A.-S.; Høgsberg, J. Active tuned mass damper for damping of offshore wind turbine vibrations. Wind Energy 2017, 20, 783-796. [CrossRef]

149. Hu, Y.; Chen, M.Z.Q.; Li, C. Active structural control for load mitigation of wind turbines via adaptive sliding-mode approach. J. Franklin Inst. 2017, 354, 4311-4330. [CrossRef]

150. Salvi, J.; Rizzi, E.; Rustighi, E.; Ferguson, N.S. On the optimization of a hybrid tuned mass damper for impulse loading. Smart Mater. Struct. 2015, 24, 085010. [CrossRef]

151. Hu, Y.; He, E. Active structural control of a floating wind turbine with a stroke-limited hybrid mass damper. J. Sound Vib. 2017, 410, 447-472. [CrossRef]

152. Cong, C. Using active tuned mass dampers with constrained stroke to simultaneously control vibrations in wind turbine blades and tower. Adv. Struct. Eng. 2019, 22, 1544-1553. [CrossRef]

153. Sun, C. Semi-active control of monopile offshore wind turbines under multi-hazards. Mech. Syst. Signal. Process. 2018, 99, 285-305. [CrossRef]

154. Park, S.; Lackner, M.A.; Pourazarm, P.; Rodríguez Tsouroukdissian, A.; Cross-Whiter, J. An investigation on the impacts of passive and semiactive structural control on a fixed bottom and a floating offshore wind turbine. Wind Energy 2019, 22, 1451-1471. [CrossRef]

155. Caterino, N. Semi-active control of a wind turbine via magnetorheological dampers. J. Sound Vib. 2015, 345, 1-17. [CrossRef]

156. Caterino, N.; Spizzuoco, M. Structural Control of a Wind Turbine Accounting for Second Order Effects. IOP Conf. Ser. Mater. Sci. Eng. 2017, 245, 022040. [CrossRef]

157. Rezaee, M.; Aly, A.M. Vibration control in wind turbines to achieve desired system-level performance under single and multiple hazard loadings. Struct. Control. Heal. Monit. 2018, 25, 1-31. [CrossRef]

158. Martynowicz, P. Vibration control of wind turbine tower-nacelle model with magnetorheological tuned vibration absorber. JVC/J. Vib. Control. 2017, 23, 3468-3489. [CrossRef] 